\title{
Repaired tetralogy of Fallot: the roles of cardiovascular magnetic resonance in evaluating pathophysiology and for pulmonary valve replacement decision support
}

\author{
Tal Geva
}

\begin{abstract}
Surgical management of tetralogy of Fallot (TOF) results in anatomic and functional abnormalities in the majority of patients. Although right ventricular volume load due to severe pulmonary regurgitation can be tolerated for many years, there is now evidence that the compensatory mechanisms of the right ventricular myocardium ultimately fail and that if the volume load is not eliminated or reduced by pulmonary valve replacement the dysfunction might be irreversible. Cardiovascular magnetic resonance (CMR) has evolved during the last 2 decades as the reference standard imaging modality to assess the anatomic and functional sequelae in patients with repaired TOF. This article reviews the pathophysiology of chronic right ventricular volume load after TOF repair and the risks and benefits of pulmonary valve replacement. The CMR techniques used to comprehensively evaluate the patient with repaired TOF are reviewed and the role of CMR in supporting clinical decisions regarding pulmonary valve replacement is discussed.
\end{abstract}

\section{Introduction}

Although the management of tetralogy of Fallot (TOF) has evolved considerably since Blalock and Taussig described the first systemic artery-to-pulmonary artery shunt in 1945 and Lillehei and Varco reported the first repair by an open-heart procedure in 1954 [1-3], optimal surgical repair has remained elusive. While early surgical mortality decreased from $50 \%$ in the late 1950 's to less than $2 \%$ in the modern surgical era [4-7], residual anatomic and hemodynamic abnormalities are nearly universal. As a result, the number of patients with repaired TOF, many of whom with considerable cardiac and non-cardiac disease burden, is growing rapidly $[8,9]$.

Right ventricular (RV) dilation from pulmonary regurgitation (PR), residual atrial and/or ventricular septal defect, tricuspid regurgitation, right ventricular outflow tract (RVOT) aneurysm, pulmonary artery stenosis, and tachyarrhythmias are some of the abnormalities frequently encountered in patients with repaired TOF.

Correspondence: tal.geva@cardio.chboston.org

Department of Cardiology, Children's Hospital Boston, Department of Pediatrics, Harvard Medical School, Boston, MA, USA
Although the hemodynamic burden associated with these anomalies is often tolerated well during childhood and adolescence, the incidences of arrhythmias, exercise intolerance, heart failure, and death nearly triple during the third postoperative decade and afterward [8-13]. Severe chronic PR-considered an important, treatable cause of RV dilatation and failure-has been the focus of many investigations in recent years. However, despite a growing body of literature on the management of severe PR after TOF repair, debate regarding the indications, methods, and optimal timing of pulmonary valve replacement (PVR) has persisted [14-17]. Cardiovascular magnetic resonance (CMR) has emerged as an essential diagnostic tool in this patient population because it overcomes many of the limitations of echocardiography, cardiac CT, and cardiac catheterization, while also providing unique quantitative data as well as prognostic information.

This article comprises two parts. The first part reviews the pathophysiology, natural history, and clinical challenges late after TOF repair. The second part discusses the role of CMR in clinical decision making with an emphasis on its role in supporting patient selection for PVR.
C Biomed Central

(c) 2011 Geva; licensee BioMed Central Ltd. This is an Open Access article distributed under the terms of the Creative Commons Attribution License (http://creativecommons.org/licenses/by/2.0), which permits unrestricted use, distribution, and reproduction in any medium, provided the original work is properly cited. 


\section{Pathophysiology of Repaired TOF}

\section{Pulmonary Regurgitation After TOF Repair}

Relief of RVOT obstruction in TOF often involves disruption of pulmonary valve integrity, which leads to $P R$ in the majority patients. Both experimental evidence and clinical data have shown that the severity of PR can increase over time [18-20]. The degree of PR is determined by (1) regurgitation orifice area; (2) RV compliance; (3) diastolic pressure difference between the main pulmonary artery (MPA) and the RV; (4) capacitance of the pulmonary arteries; and (5) duration of diastole. Some of the key factors influencing PR volume are captured by the Torricelli principle [21]:

$$
\mathrm{PR} \text { volume }=\mathrm{ROA} \cdot \mathrm{C} \cdot \mathrm{DT} \cdot\left(\mathrm{P}_{2}-\mathrm{P}_{1}\right)^{0.5}
$$

Where $\mathrm{ROA}=$ regurgitation orifice area; $\mathrm{C}=$ constant (empiric number); $\mathrm{DT}=$ diastolic time; $\left(\mathrm{P}_{2}-\mathrm{P}_{1}\right)=$ mean diastolic pressure difference between the MPA and RV. Unlike aortic regurgitation, the diastolic pressure difference between the MPA and the RV is small. Therefore, the PR volume is largely determined by other factors, namely the size of the regurgitation orifice (typically large after TOF repair), the capacitance of the pulmonary arteries [22], and duration of diastole (related to heart rate). Other factors such as pulmonary vascular resistance and LV function may also influence PR.

At the time of TOF repair, the RV is hypertrophied and its compliance is low; the diameters of the central pulmonary arteries are either hypoplastic or low-normal, and their capacitance is low; and the heart rate is relatively high, which leads to a relatively short duration of diastole. Therefore, despite a relatively large regurgitation orifice immediately after TOF repair, the combination of factors described above minimizes the impact of PR. Over time, however, the increase in RV stroke volume leads to progressive rise in the size and capacitance of the central pulmonary arteries and to RV dilatation. Combined with a longer duration of diastole as heart rate decreases with age, these changes lead to progressive increase in the degree of PR (Figure 1). Experimental evidence supporting this progression was provided by Kuehne et al. who demonstrated in growing swines with a stented pulmonary valve an increase in PR fraction from $33 \pm 7 \%$ at baseline to $49 \pm 6 \%$ at 3 months [19]. Progression of PR, however, likely plateaus at some point but quantitative longitudinal data documenting this assumption is lacking.

Effects of Chronic Volume Load on Ventricular Mechanics A growing clinical experience and experimental evidence point to striking similarities between the pathophysiologic response of the left and right ventricles to severe chronic volume load. Moreover, in-vitro studies have

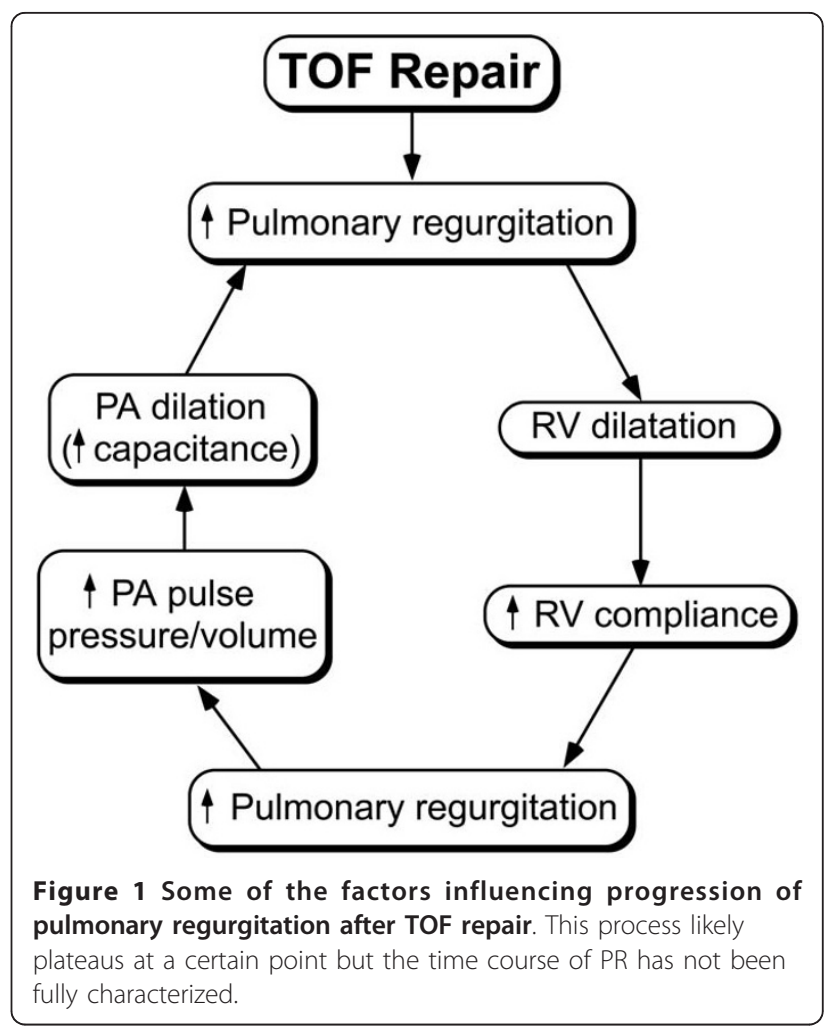

shown similar intrinsic properties of myofibers from the left and right ventricles, including their response to pressure and volume overload conditions [23,24]. Because the pathophysiology of left ventricular (LV) response to chronic aortic regurgitation has been studied in great detail [25-27], it is worth considering the sequence of events here. Investigators divide the pathophysiologic response of the LV to severe chronic aortic regurgitation into 4 stages of variable duration: 1) A compensated stage characterized by an increase in enddiastolic volume and a combination of eccentric and concentric hypertrophy. At the cellular level, ventricular dilatation is characterized by cellular elongation, addition of myofibers, and a decrease in collagen content. At the pump level, these changes lead to an increase in end-diastolic volume and maintenance of relatively normal mass-to-volume ratio (compensated hypertrophy), end-systolic fiber stress, and global systolic function. An increase in stroke volume maintains net forward flow within normal limits. This stage may last for many years or even decades. 2) Failure of compensatory mechanisms. This stage is characterized by continued LV dilatation but with decreased mass-to-volume ratio (inadequate hypertrophy) and increased afterload (endsystolic stress). As a result, the rate and magnitude of fiber shortening decrease. This stage manifests as decreased global systolic function while intrinsic myocardial contractility remains relatively normal. 
3) Reduced but reversible myocardial contractility. Over the short term, the impaired contractility may be reversible, and elimination of the volume load can result in recovery of pump function. 4) Irreversible myocardial injury associated with fibrosis and increased interstitial collagen [28]. Although valve replacement may still be tolerated and of clinical benefit [27,29], myocardial dysfunction persists.

Similar to the above-described course of LV response to volume load, patients usually tolerate chronic RV volume load without symptoms for many years. Indeed some investigators in the 1970 s and 1980s considered PR benign [30]. Isolated congenital $\mathrm{PR}-\mathrm{a}$ rare cardiac anomaly similar to TOF with absent pulmonary valve syndrome but without ventricular septal defect-offers a unique opportunity to examine the long-term effects of severe chronic PR without the confounding effects of cyanosis, ventricular septal defect, pulmonary stenosis, or the sequelae of cardiac surgery. In a review of 72 such cases reported in the literature [31], Shimazaki et al. found that that the annualized probability of developing symptoms of heart failure increased exponentially over time, mostly after age 40 years. Similarly, studies of patients with a secundum atrial septal defect, which also results in isolated RV volume overload, have demonstrated that the volume load adversely affects both right and left ventricular geometry and function and that these abnormalities are fully reversible when the shunt is eliminated early in life [32-36]. However, functional recovery is less complete when an atrial septal defect is closed later in life [37-39]. Taken together, these studies show that "isolated" RV volume load can be tolerated with little or no symptoms during the first 3-4 decades of life and elimination of the volume load during that period usually leads to full functional recovery. Left untreated, however, continued RV volume load is associated with an accelerated rate of progressive symptoms and incomplete functional recovery of RV systolic and diastolic function.

\section{RV Mechanics After TOF Repair}

Although the pathophysiology of RV remodeling in response to the altered hemodynamic conditions after TOF repair is strikingly similar to the response of the LV to chronic volume load, important differences exist. Examples include chamber geometry, myofiber architecture, chamber contraction pattern, coronary artery anatomy and flow dynamic, disposition of the conduction system, and dependency on LV size and function [40]. The RV comprises two distinct embryologic components-the sinus and the infundibulum-with a complex shape. The myocardium comprises a relatively thin compact layer and a prominent layer of trabeculations interspersed with deep recesses. In contrast to the LV, the orientation of the myofibers in the $\mathrm{RV}$ is more horizontal and contraction is predominantly from base-to-apex (longitudinal) with a lower degree of angular motion (twist). The myocardium is supplied by a single coronary artery with nearly $50 \%$ of the flow occurring during diastole under normal conditions as oppose to $\sim 90 \%$ in the LV. The conduction system in the RV comprises a single fascicle with a long course and a long delay in activation between the base and the distal infundibular free wall, resulting in peristalsislike motion [41]. Although RV function impacts $\mathrm{LV}$ function, the reverse is much more pronounced with $63 \%$ of $\mathrm{RV}$ pressure rise accounted for by $\mathrm{LV}$ contraction.

After TOF repair, additional factors related to the operation further impact the pathophysiology. Relief of RV outflow obstruction typically involves incision of the infundibular free wall, resection of obstructive muscle bundles, disruption of the pulmonary valve with partial or complete excision, and placement of an outflow patch, which often extends across the plane of the pulmonary valve into the MPA. In some patients a conduit between the RV and the pulmonary arteries is required to provide antegrade pulmonary blood flow. The ventricular septal defect is closed with a patch, a procedure that can impair tricuspid valve function. In addition to the nearly universal occurrence of PR (discussed above), these procedures often lead to akinesis or dyskinesis of the RVOT, outflow patch aneurysm (Figure 2), fibrosis of the RV free wall, and conduction delay [42]. Table 1

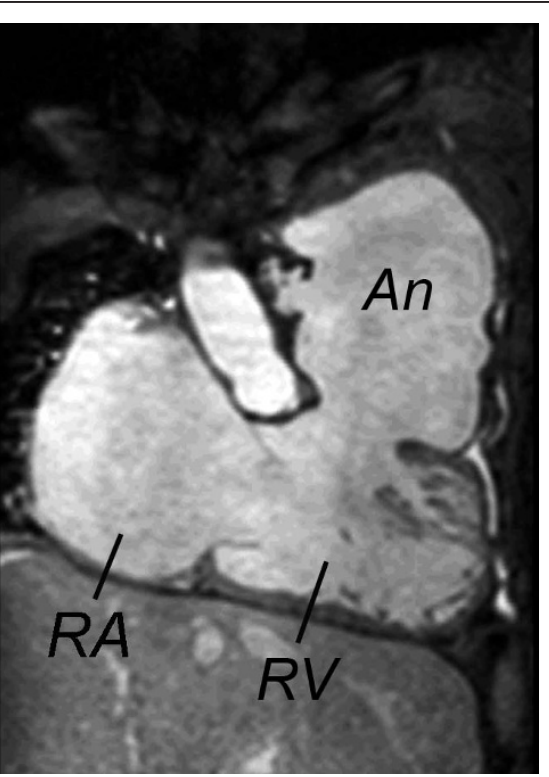

Figure 2 Steady-state free precession cine CMR of the right ventricular (RV) inflow and outflow showing a large outflow tract patch aneurysm (An). RA = right atrium. 
Table 1 Structural and functional abnormalities encountered in repaired TOF

\begin{tabular}{lc}
\hline Structural Abnormalities & Functional Abnormalities \\
\hline Inherent to TOF repair & RV volume overload \\
Partial or complete removal of pulmonary valve tissue & Pulmonary regurgitation \\
Infundibulotomy scar & Tricuspid regurgitation \\
Resection of RV/infundibular muscle bundles & Left-to-right shunt \\
Right atriotomy scar & Ventricular septal defect \\
VSD patch & Atrial septal defect \\
Residual or recurrent lesions & Aorto-pulmonary collaterals \\
RV outflow tract obstruction & RV pressure overload \\
Main or branch pulmonary artery stenosis & RV outflow or pulmonary artery stenosis \\
Ventricular septal defect & Pulmonary vascular disease \\
Atrial septal defect & Pulmonary venous hypertension secondary to LV dysfunction \\
Acquired lesions & RV systolic dysfunction \\
Tricuspid valve abnormalities & RV diastolic dysfunction \\
RV outflow tract aneurysm & LV dysfunction \\
RV fibrosis & Ventricular conduction delay \\
Associated anomalies & Arrhythmias \\
Dilated aorta & Atrial flutter \\
Associated congenital cardiovascular anomalies & Atrial fibrillation \\
Associated genetic and non-cardiac anomalies & Ventricular tachycardia \\
& Co-morbidities \\
& Renal, pulmonary, musculoskeletal, neurodevelopmental abnormalities \\
\hline
\end{tabular}

summarizes the structural and functional abnormalities after TOF repair.

Studies in animal models of RV volume load similar to conditions seen after TOF repair provide insight into myocardial adaptation. Kiriazis et al. studied an in-vitro preparation of RV papillary muscle subjected to volume load [43]. They showed that peak stress development and other markers of myocardial mechanics and energy were normal in a stage of compensated hypertrophy but reduced in uncompensated volume load. Kuehne et al. used CMR and conductance catheter techniques to investigate the effects of PR on biventricular mechanics in a growing swine model [19]. Compared with control animals, indices of RV systolic function (ejection fraction, peak $\mathrm{dP} / \mathrm{dt}$, and $\mathrm{E}_{\max }$ ) were significantly reduced 3 months after induction of PR.

Human studies in repaired TOF patients using CMR provide insights regarding ventricular mechanics and clinical outcomes in this population [10,44-47]. Several authors have demonstrated a close relationship between the degree of PR and RV diastolic dimensions and stroke volume (Figure 3) [48-51]. Similar to LV function in severe chronic aortic regurgitation, once the compensatory mechanisms of the RV fail, mass-to-volume ratio decreases, end-systolic volume increases, and ejection fraction decreases (Figure 4). Kurotobi et al. demonstrated an association between an increase in RV wall stress (afterload), decreased RV ejection fraction, and symptoms in patients with repaired TOF [52]. Other factors that adversely affect RV mechanics include the spatial extent and magnitude of dyskinesis of the outflow patch (Figure 5), [19,42] RV fibrosis [42,45,53], impaired RV diastolic function, [49,54-58] and left ventricular dysfunction [10,45,59-61]. Prolonged conduction time and dyssynchrony of RV contraction likely further contribute to RV dysfunction. An older age of repair is another independent risk factor for adverse outcome in these patients $[10,13,62]$. Similar to the natural history of severe aortic regurgitation, in which irreversible myocardial damage follows a period of reversible ventricular

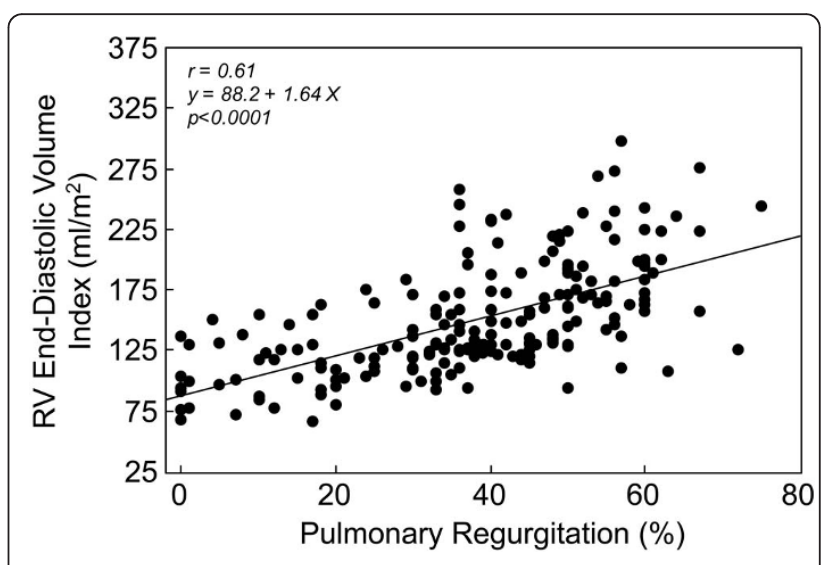

Figure 3 Correlation between pulmonary regurgitation and right ventricular (RV) end-diastolic volume index in 206 patients with repaired TOF [46]. 


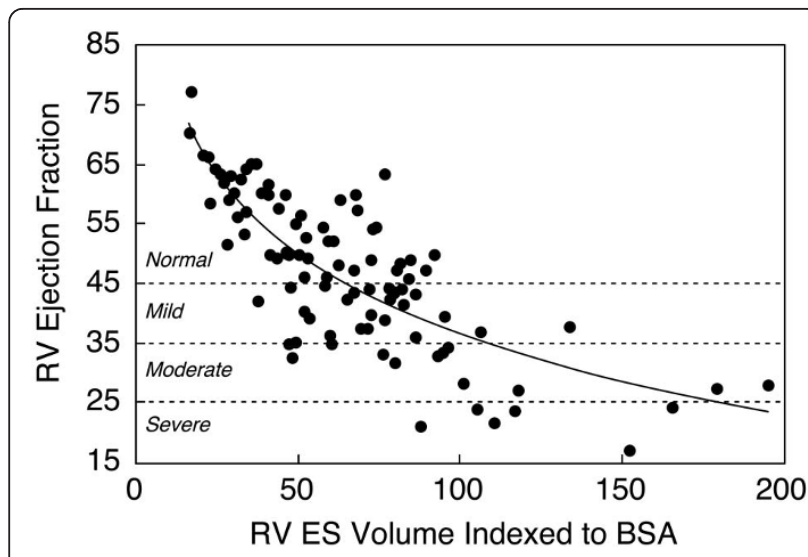

Figure 4 Relationship between right ventricular end-systolic volume and RV ejection fraction in 100 patients with repaired TOF (Spearman rank correlation coefficient $\left(r_{s}\right)=-0.77 ; p<$ 0.001) [10]. dysfunction, evidence suggests that the same occurs late after TOF repair $[15,63]$. Figure 6 summarizes the pathophysiologic pathway that leads to ventricular dysfunction and heart failure after TOF repair.

\section{RV-LV Interaction After TOF Repair}

The right and left ventricles function in series and, in the absence of shunts, have similar net outputs. In 1910 the French physiologist Bernheim first recognized interdependence between LV and RV function. He postulated that alterations in the size and function of the LV adversely impact the geometry and function of the RV, a phenomenon termed 'Bernheim effect' [64]. Many subsequent studies have demonstrated that alterations in the size and function of the RV lead to LV dysfunction, a phenomenon termed 'reversed Bernheim effect' [65]. Ventricular-ventricular interaction occurs because the ventricles share myofibers [66], septum, coronary blood
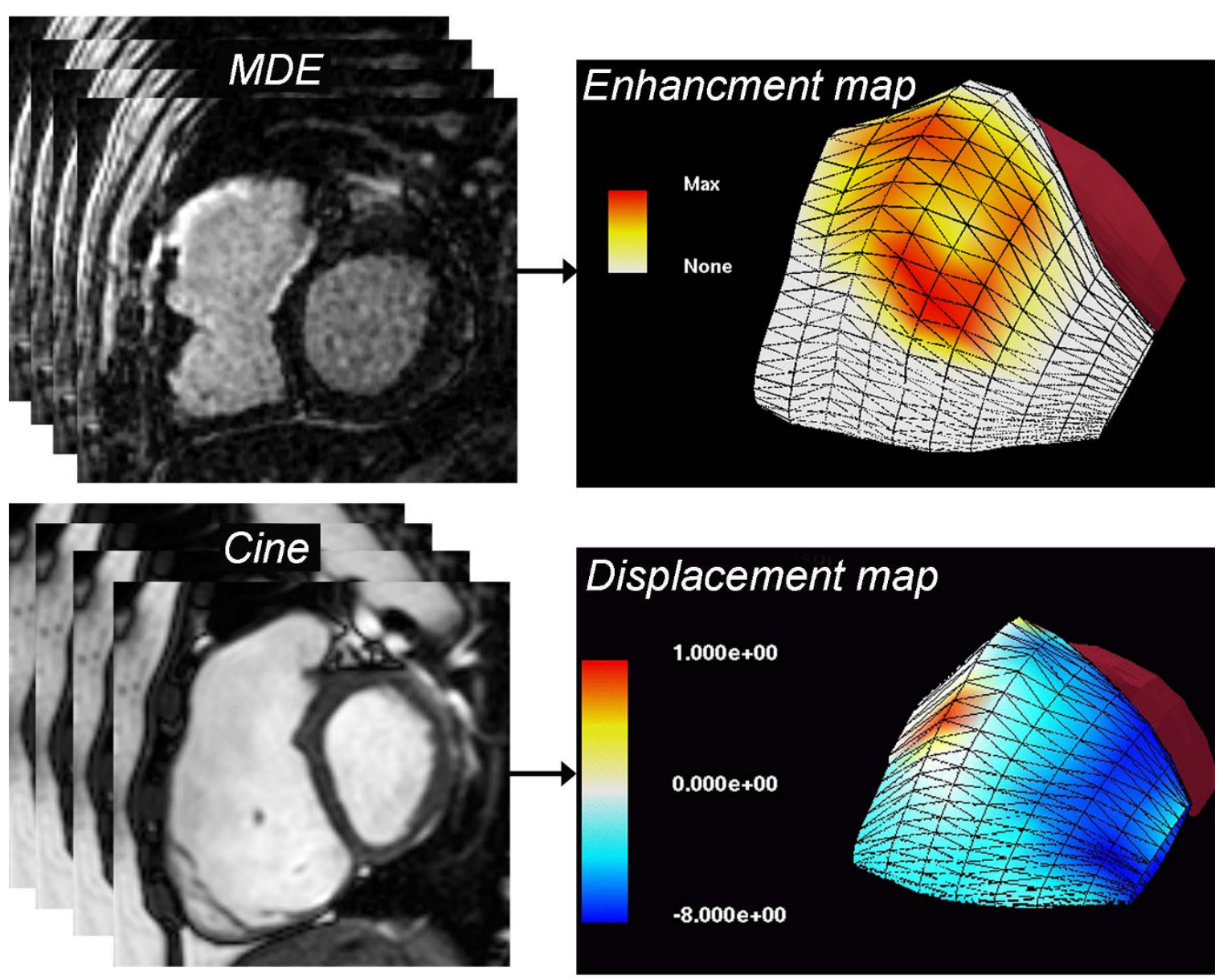

Figure 5 Three-dimensional surface models of the right ventricular (RV) free wall reconstructed from multi-slice 2-dimensional shortand long-axis images. Top panel: Scar tissue map based on late gadolinium enhancement (LGE) imaging showing extensive late

hyperenhancement of the RVOT (yellow and orange). Bottom panel: Displacement map based on multi-slice cine SSFP showing dyskinesis of the RVOT (red). See Wald et al. for further technical details [42]. 


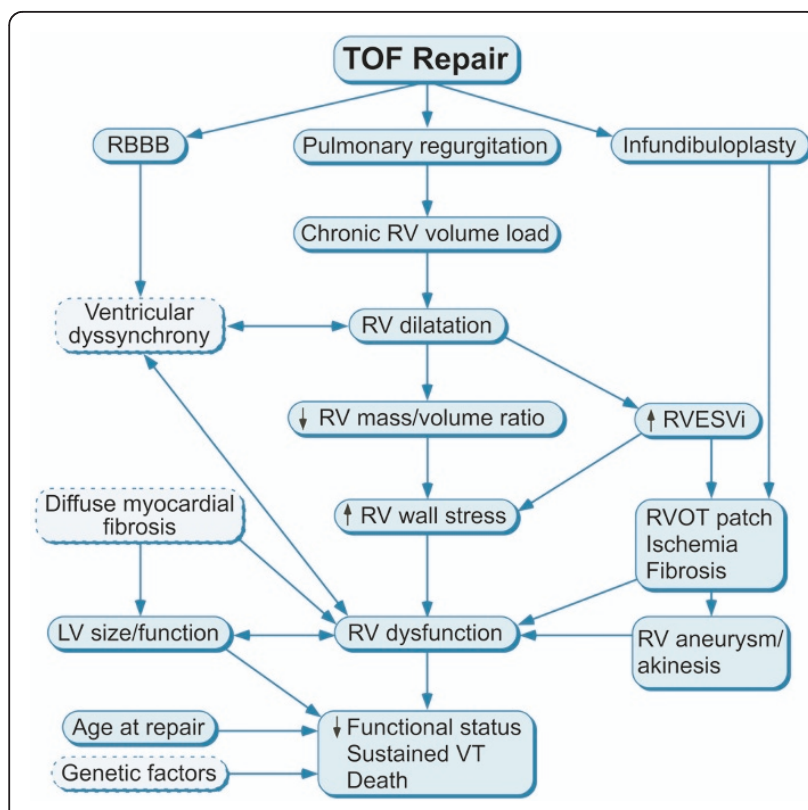

Figure 6 Factors influencing right ventricular (RV) dysfunction and impaired clinical status after TOF repair.

flow, and pericardial space. The superficial spiraling layer of RV myofibers is continuous with the superficial layer of the LV whereas the deep layer of RV myofibers is continuous with that of the LV through the interventricular septum.

The adverse impact of RV dilatation and dysfunction on LV geometry and function (both diastolic and systolic) has been demonstrated in patients with congenital (e.g., atrial septal defect, Ebstein anomaly) and acquired heart disease (e.g., pulmonary embolus, primary pulmonary hypertension). Through a complex interplay involving the shared myofibers, septum, pericardium, and coronary flow, RV volume load leads to septal shift towards the LV, leftward shift of the LV pressure-volume loop, and reduction in LV operant volumes. Initially, LV function is preserved but with progressive RV dysfunction, LV function deteriorates. Ventricular dyssynchrony, both intraand inter-ventricular, likely contribute to adverse RV-LV interaction $[60,67]$. In the previously mentioned study of Kuehne et al. [19], the response of both the RV and LV to dobutamine stress was markedly blunted, suggesting that LV function is adversely influenced by impaired RV mechanics. A clinical study using CMR in patients with repaired TOF demonstrated a close linear correlation between the ejection fraction of the RV and that of the LV (Figure 7) [10].

\section{Natural History And Outcomes After Tof Repair}

Early survival of patients with TOF is excellent with $1-2 \%$ operative mortality $[68,69]$. Two large cohort studies of patients with repaired TOF have shown that

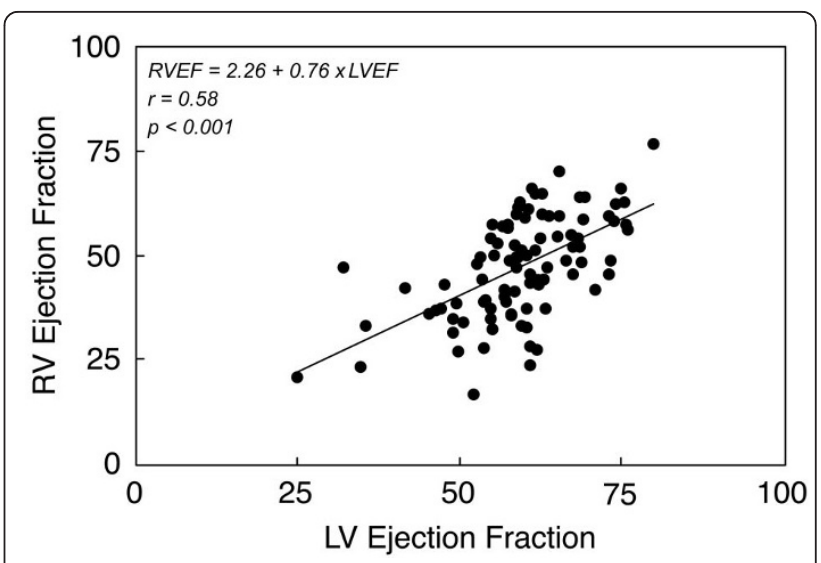

Figure 7 Association between right ventricular (RV) and left ventricular (LV) ejection fraction (EF) in 100 patients with repaired TOF [10].

survival continues at $\sim 90 \%$ during the first two decades of life $[8,9]$. However, mortality rate nearly triples during the third postoperative decade. Numerous studies have shown that late after TOF repair patients are at risk for exercise intolerance, heart failure, arrhythmias, and death [10,47,70-79]. In addition, pulmonary, renal, hepatic, musculoskeletal, and other non-cardiac morbidities often complicate the clinical course of these patients [47].

The common theme that has emerged from the literature on risk stratification of major adverse events (death, ventricular tachycardia, and heart failure) late after TOF repair is that there are 3 major categories of outcome predictors: 1) history (syncope, older age at repair); 2) electrophysiological markers (prolonged QRS duration, sustained ventricular tachycardia); and 3) hemodynamic sequelae of severe PR (RV dilatation, ventricular dysfunction, and regional wall motion abnormalities).

Multiple studies have addressed risk factors for sudden death and for tachyarrhythmias late after TOF repair. Gatzoulis et al. studied 793 patients from 6 centers [80]. They found that an older age at repair and QRS duration $\geq 180 \mathrm{~ms}$ were independent predictors of sudden death. Moderate or severe PR was the main hemodynamic abnormality in patients with ventricular tachycardia and sudden death, whereas tricuspid regurgitation was associated with supraventricular arrhythmias. Khairy et al., in a multicenter study of 252 patients with repaired TOF, found that a positive programmed ventricular stimulation study, history of syncope, moderate or severe pulmonary or tricuspid regurgitation, QRS duration $\geq 180 \mathrm{~ms}$, cardiomegaly on chest radiogram (cardio-thoracic ratio $\geq 0.6$ ), and multifocal premature ventricular contractions were associated with sudden death or clinical ventricular tachycardia [79]. Harrison et al. found that patients with sustained 
ventricular tachycardia were more likely to have RVOT aneurysms and severe PR [81]. Ghai et al., in a study that compared 12 adult patients who died late after TOF repair to 125 control patients, found that patients who died were more likely to have history of sustained ventricular tachycardia, prolonged QRS duration $\geq 180$ ms, moderate or severe PR, and moderate or severe left ventricular dysfunction [59]. It is worth noting that in none of these studies was RV size or function quantified.

In a study that used CMR to measure PR and biventricular dimensions and function in 100 late survivors of TOF repair, RV and LV dysfunction were strongly associated with impaired clinical status, but the degree of PR was not [10]. Instead, the severity of PR was mainly related to the degree of RV enlargement, a finding that concurs with other studies that utilized CMR to assess these variables $[49,82]$. Knauth et al., in a follow-up study of the previous cohort, found that severe RV dilatation (end-diastolic volume Z-score $\geq 7$ measured by CMR) and ventricular dysfunction (LV EF $<55 \%$ or RV $\mathrm{EF}<45 \%$ ) were independent predictors of adverse outcomes (death, sustained ventricular tachycardia, heart failure) [47]. Other univariate predictors were older age at TOF repair and QRS duration $\geq 180 \mathrm{~ms}$. Importantly, QRS duration correlated closely with RV end-diastolic volume and, therefore, lost statistical significance in a multivariate model. Other investigators have also reported a similarly close association between QRS duration and RV size $[83,84]$. Myocardial fibrosis, RVOT aneurysm, and regional wall motion abnormalities have also been associated with symptoms, exercise intolerance, and arrhythmias $[42,45,53,85]$.

\section{Treatment Strategies Late After Tof Repair} Indications and Timing of Pulmonary Valve Replacement Recommendation for PVR in patients with repaired TOF and severe PR are based on risk/benefit analysis that takes into account the natural history and pathophysiology of the disease, procedural risks, and its potential benefits.

\section{Risks of Pulmonary Valve Replacement}

The operative mortality for surgical PVR is low (Table 2). There is, however, continued low risk of death after PVR. Therrien et al. reported 92\% survival at 5 years and $86 \%$ at 10 years in 70 adult patients after PVR [86]. Discigil et al. reported 95\% survival at 5 years and $76 \%$ at 10 years in 42 patients [87]. Harrild et al. followed 98 patients after PVR (age at PVR $25 \pm$ 13 years). Freedom from death and/or ventricular tachycardia was $80 \%$ at 5 years and $41 \%$ at 10 years, and the event incidence was 4.8 per 100 patient-years [88].

When considering the risks associated with PVR, the risk of valve failure should also be considered. All

Table 2 Perioperative and late mortality of pulmonary valve replacement after TOF repair

\begin{tabular}{|c|c|c|c|c|c|}
\hline Institution & Year & $\begin{array}{l}\text { Number of } \\
\text { Patients }\end{array}$ & $\begin{array}{l}\text { Operative } \\
\text { Death }\end{array}$ & $\begin{array}{l}\text { Average Length } \\
\text { of Follow-Up } \\
\text { (years) }\end{array}$ & $\begin{array}{l}\text { Late Death } \\
\text { or } \\
\text { transplant }\end{array}$ \\
\hline SUNY, Syracuse [142] & 1985 & 11 & 0 & 1 & 0 \\
\hline $\begin{array}{l}\text { Children's Memorial Hospital, } \\
\text { Chicago [143] }\end{array}$ & 1997 & 49 & 1 & & \\
\hline University of Toronto [101] & 1997 & 85 & 1 & 5.8 & 3 \\
\hline Mayo Clinic [87] & 2001 & 42 & 1 & & \\
\hline Children's Hospital, Atlanta [144] & 2002 & 100 & 1 & 4.9 & 1 \\
\hline $\begin{array}{l}\text { Leiden University, The Netherlands } \\
\text { [97] }\end{array}$ & 2002 & 26 & 0 & 1.5 & 1 \\
\hline $\begin{array}{l}\text { New England Med Center, Boston } \\
\text { [105] }\end{array}$ & 2003 & 36 & 0 & 5 & 1 \\
\hline $\begin{array}{l}\text { University of Zurich, Switzerland } \\
{[100]}\end{array}$ & 2005 & 39 & 0 & 1.25 & 0 \\
\hline Multicenter, The Netherlands [145] & 2006 & 158 & 0 & 4.2 & 2 \\
\hline University of Toronto [99] & 2007 & 82 & 0 & 8.8 & 2 \\
\hline $\begin{array}{l}\text { University Medical Center, } \\
\text { Rotterdam [14] }\end{array}$ & 2008 & 17 & 0 & 6.4 & 0 \\
\hline $\begin{array}{l}\text { International Society of Congenital } \\
\text { Heart Disease [107] }\end{array}$ & 2008 & 93 & 0 & 3 & 2 \\
\hline Great Ormond Street, London[94] & 2008 & 71 & 0 & 1 & 0 \\
\hline Emory University [146] & 2009 & 107 & 3 & & \\
\hline Children's Hospital Boston [88] & 2009 & 77 & 0 & 2.8 & 6 \\
\hline \multirow[t]{2}{*}{ Children's Hospital, Atlanta [147] } & 2010 & 42 & 0 & 2.2 & 0 \\
\hline & & 1035 & $0.68 \%$ & & $2.2 \%$ \\
\hline
\end{tabular}


valves inserted in the pulmonary position have a limited life expectancy, with wide variations in rates of freedom from valve failure and reoperation, depending of the type of valve and patient age. Calderone et al. reported freedom from reoperation in $81 \%$ of patients at 5 years, $58 \%$ at 10 years, and $41 \%$ at 15 years [89]. These authors, as well as many others, have shown that young age at pulmonary valve placement is associated with a higher rate of valve failure and early reoperation.

The advent of transcatheter pulmonary valve implantation $[90,91]$, however, may provide a new non-surgical option for the treatment of failed bioprosthetic pulmonary valve. Although the currently available catheterdelivered, stent-mounted valves are limited by the size and geometry of the RVOT to mostly patients with RV-to-pulmonary artery conduits, future developments will likely expand the clinical application of this technique to patients with dilated RVOT. Even with currently available technology, catheter-based pulmonary valve implantation can be performed inside a failing bioprosthetic valve or conduit [92]. Further development of this technology may reduce the need for reoperation after pulmonary valve implantation and will likely lower the threshold for restoring pulmonary valve competency in patients with chronic PR.

\section{Benefits of Pulmonary Valve Replacement}

There is strong evidence that PVR is highly effective in eliminating or greatly reducing PR [93-95]. Multiple studies published during the past decade have painted a consistent picture regarding the clinical response and the mechanical adaptation of the right and left ventricles to PVR [96]. Table 3 summarizes findings from 10 representative studies. Clinically, many patients report less cardiac symptoms after PVR and several studies have reported a significant improvement in NYHA functional class [15,93-95,97-99]. Within approximately one year after PVR RV end-diastolic and end-systolic volumes decrease by $30-40 \%$ as compared with their preoperative values. On average, global RV systolic function (measured as ejection fraction) remains unchanged. LV end-diastolic volume increases slightly whereas global LV systolic function remains unchanged $[15,16,63,86,87,95,100-103]$. The degree of tricuspid valve regurgitation (evaluated by Doppler echocardiography) tends to improve with or without concomitant tricuspid valve surgery. The percent of patients with at least moderate tricuspid regurgitation decreased from $25 \%$ before PVR to $5 \%$ after surgery in the study of Buechel et al. [16], from $24 \%$ to $0 \%$ in the study of Therrien et al. [15], and from $13 \%$ to $2 \%$ in the study of Geva et al [95].

The data regarding the effects of PVR on QRS duration, arrhythmia propensity, and objective exercise parameters is inconsistent. Some investigators have reported modest improvements in one or more of these categories whereas others have shown no significant change from pre- to post-PVR. Therrien et al. reported that the incidence of ventricular tachycardia was lower after PVR (9\% post operatively versus $23 \%$ preoperatively) and that the rate of increase in QRS duration had stabilized after the procedure [86]. In contrast, Harrild et al. and Gengsakul et al. found no significant improvement in the frequency of arrhythmias after PVR $[88,99]$. Similarly conflicting results have been reported regarding decrease in QRS duration from pre- to post-PVR $[16,84,88,95,104]$. Finally, whereas some investigators have reported that certain indices of exercise tolerance improve $[94,102,105]$, others have not found such improvement $[95,106]$.

\section{Rationale and Timing of Pulmonary Valve Replacement}

Although conclusive confirmation that PVR improves survival late after TOF repair is still lacking, a growing body of evidence has emerged during the last decade supporting the rationale for the procedure. There is strong evidence that without intervention severe PR in repaired TOF leads to severe RV dilatation and dysfunction, tricuspid valve regurgitation, LV dysfunction, tachyarrhythmias, diminished exercise tolerance, heart failure symptoms, and death (Additional file 1) $[8-10,59,80]$. As discussed above, PVR leads to elimination or marked reduction of $\mathrm{PR}$, improved biventricular mechanics, improvement in tricuspid regurgitation, and symptomatic improvement. For many years most centers have referred patients with severe chronic PR for PVR based on overt symptoms, such as progressive exercise intolerance, heart failure symptoms, syncope, or ventricular tachycardia $[17,63,88,107]$. Recent evidence clearly demonstrates that relying on symptoms as the major criteria for PVR results in patients receiving a pulmonary valve when their RV is markedly dilated (mean RV end-diastolic volume $201 \pm 37 \mathrm{ml} / \mathrm{m}^{2}$ in one study [95]), and RV and/or LV dysfunction is present (Figure 8). Several studies have identified pre-PVR threshold values of RV end-diastolic and end-systolic volumes that are associated with postoperative normalization of RV size. Therrien et al. reported that RV size did not return to normal in any of the 7 patients whose pre-operative end-diastolic volume index was $>170 \mathrm{ml} / \mathrm{m}^{2}$, whereas RV size normalized in 9 of 10 patients with pre-operative end-diastolic volume $\leq 170 \mathrm{ml} / \mathrm{m}^{2}$ [15]. Oosterhof et al. identified RV end-diastolic volume $<160 \mathrm{ml} / \mathrm{m}^{2}$ and end-systolic volume $<82 \mathrm{ml} / \mathrm{m}^{2}$ as associated with normal postoperative RV size [93]. Buechel et al. identified RV end-diastolic volume $<150 \mathrm{ml} / \mathrm{m}^{2}$ as the threshold value below which RV size returns to the normal range after PVR [16]. Frigiola et al. have adopted an institutional policy of recommending PVR in 
Table 3 Effects of pulmonary valve replacement on ventricular mechanics, QRS duration, peak oxygen consumption, and functional class

\begin{tabular}{|c|c|c|c|c|c|c|c|c|c|c|c|c|c|c|c|c|c|c|}
\hline & \multicolumn{2}{|c|}{ PR (\%) } & \multicolumn{2}{|c|}{$\begin{array}{l}\text { RVEDVi } \\
\left(\mathrm{ml} / \mathrm{m}^{2}\right)\end{array}$} & \multicolumn{2}{|c|}{$\begin{array}{l}\text { RVESVi } \\
\left(\mathrm{ml} / \mathrm{m}^{2}\right)\end{array}$} & \multicolumn{2}{|c|}{ RV EF (\%) } & \multicolumn{2}{|c|}{$\begin{array}{l}\text { LVEDVi } \\
\left(\mathrm{ml} / \mathrm{m}^{2}\right)\end{array}$} & \multicolumn{2}{|c|}{ LV EF (\%) } & \multicolumn{2}{|c|}{$\begin{array}{l}\text { QRS duration } \\
\text { (ms) }\end{array}$} & \multicolumn{2}{|c|}{$\begin{array}{c}\text { Peak } \mathrm{O}_{2} \\
\text { consumption } \\
\text { (ml } / \mathrm{kg} / \mathrm{min})\end{array}$} & \multicolumn{2}{|c|}{ NYHA class } \\
\hline & Before & After & Before & After & Before & After & Before & After & Before & After & Before & After & Before & After & Before & After & Before & After \\
\hline $\begin{array}{l}\text { Vliegen et al. [97] } \\
N=26 \\
\text { Age: } 29 \pm 9 \text { years }\end{array}$ & $\begin{array}{c}46 \pm \\
10\end{array}$ & $\begin{array}{c}4 \pm \\
8\end{array}$ & $\begin{array}{c}167 \pm \\
40\end{array}$ & $\begin{array}{c}114 \pm \\
35\end{array}$ & $99 \pm 36$ & $\begin{array}{l}66 \pm \\
35\end{array}$ & $\begin{array}{c}42 \pm \\
10\end{array}$ & $\begin{array}{l}42 \pm \\
11\end{array}$ & $\begin{array}{c}86 \pm \\
29\end{array}$ & $\begin{array}{c}87 \pm \\
17\end{array}$ & & & & & & & $2.0 \pm 0.6$ & $1.3 \pm 0.5$ \\
\hline $\begin{array}{l}\text { Therrien et al. [15] } \\
\mathrm{N}=17 \\
\text { Age: } 32 \text { years }\end{array}$ & & & $\begin{array}{c}163 \pm \\
34\end{array}$ & $\begin{array}{l}107 \pm \\
26\end{array}$ & $\begin{array}{c}109 \pm \\
27\end{array}$ & $\begin{array}{l}69 \pm \\
22\end{array}$ & $32 \pm 7$ & $\begin{array}{l}34 \pm \\
10\end{array}$ & & & & & & & & & $2.0 \pm 1.0$ & $1.4 \pm 0.5$ \\
\hline $\begin{array}{l}\text { van Straten et al. } \\
{[148]} \\
N=16 \\
\text { Age: } 29 \text { years }\end{array}$ & $\begin{array}{c}48 \pm \\
10\end{array}$ & $\begin{array}{c}3 \pm \\
5\end{array}$ & $\begin{array}{c}164 \pm \\
43\end{array}$ & $\begin{array}{c}113 \pm \\
26\end{array}$ & $94 \pm 33$ & $\begin{array}{c}61 \pm \\
18\end{array}$ & $44 \pm 8$ & $\begin{array}{c}47 \pm \\
12\end{array}$ & & & & & & & & & & \\
\hline $\begin{array}{l}\text { Doughan et al. [84] } \\
N=21 \\
\text { Age: } 34 \pm 9 \text { years }\end{array}$ & & & & & & & & & & & & & $153 \pm 34$ & $142 \pm 29$ & & & & \\
\hline $\begin{array}{l}\text { Buechel et al. [16] } \\
N=20 \\
\text { Age: } 14 \pm 3 \text { years }\end{array}$ & $\begin{array}{c}49 \pm \\
14\end{array}$ & $\begin{array}{c}9 \pm \\
8\end{array}$ & $\begin{array}{c}190 \pm \\
33\end{array}$ & $\begin{array}{l}109 \pm \\
26\end{array}$ & $\begin{array}{c}102 \pm \\
27\end{array}$ & $\begin{array}{c}58 \pm \\
16\end{array}$ & $47 \pm 7$ & $45 \pm 9$ & $\begin{array}{c}77 \pm \\
10\end{array}$ & $\begin{array}{c}84 \pm \\
12\end{array}$ & $53 \pm 6$ & $\begin{array}{c}56 \pm \\
7\end{array}$ & $150 \pm 18$ & $148 \pm 17$ & & & & \\
\hline $\begin{array}{l}\text { Henkens et al. [98] } \\
N=27 \\
\text { Age: } 31 \pm 8 \text { years }\end{array}$ & $\begin{array}{c}48 \pm \\
11\end{array}$ & & 166 & 100 & 98 & 58 & $\begin{array}{c}42 \pm \\
10\end{array}$ & $\begin{array}{l}43 \pm \\
10\end{array}$ & $\begin{array}{c}89 \pm \\
31\end{array}$ & $\begin{array}{c}87 \pm \\
18\end{array}$ & $\begin{array}{c}56 \pm \\
12\end{array}$ & $\begin{array}{l}55 \pm \\
9\end{array}$ & & & & & $2.0 \pm 0.6$ & $1.3 \pm 0.3$ \\
\hline $\begin{array}{l}\text { Oosterhof et al. } \\
{[93]} \\
N=71 \\
\text { Age: } 29 \text { years }\end{array}$ & $\begin{array}{c}44 \pm \\
13\end{array}$ & $\begin{array}{l}5 \pm \\
9\end{array}$ & $\begin{array}{c}171 \pm \\
44\end{array}$ & $\begin{array}{l}119 \pm \\
34\end{array}$ & $\begin{array}{l}102 \pm \\
38\end{array}$ & $\begin{array}{l}70 \pm \\
29\end{array}$ & $\begin{array}{c}42 \pm \\
10\end{array}$ & $\begin{array}{l}43 \pm \\
10\end{array}$ & $\begin{array}{c}85 \pm \\
22\end{array}$ & $\begin{array}{c}94 \pm \\
20\end{array}$ & $52 \pm 9$ & $\begin{array}{c}53 \pm \\
8\end{array}$ & $155 \pm 29$ & $144 \pm 29$ & & & $\begin{array}{c}53 \% \text { grade } \\
\geq \| 1\end{array}$ & $\begin{array}{c}11 \% \text { grade } \\
\geq \| 11\end{array}$ \\
\hline $\begin{array}{l}\text { Gengsakul et al. } \\
{[99]} \\
N=82 \\
\text { Age: } 28 \pm 13 \text { years }\end{array}$ & & & & & & & & & & & & & $164 \pm 21$ & $168 \pm 21$ & & & $\begin{array}{c}54 \% \text { grade } \\
\geq \| 1\end{array}$ & $\begin{array}{c}13 \% \text { grade } \\
\geq \| 1\end{array}$ \\
\hline $\begin{array}{l}\text { Frigiola et al. }[94] \\
N=71 \\
\text { Age } 22 \pm 11 \text { years }\end{array}$ & $41 \pm 9$ & $\begin{array}{c}5 \pm \\
7\end{array}$ & $\begin{array}{l}142 \pm \\
43\end{array}$ & $91 \pm 18$ & $73 \pm 33$ & $\begin{array}{c}43 \pm \\
14\end{array}$ & $\begin{array}{c}51 \pm \\
10\end{array}$ & $54 \pm 7$ & $\begin{array}{c}66 \pm \\
12\end{array}$ & $\begin{array}{c}73 \pm \\
13\end{array}$ & $61 \pm 8$ & $\begin{array}{c}64 \pm \\
7\end{array}$ & & & $25 \pm 10$ & $25 \pm 9$ & 2.0 & 1.0 \\
\hline $\begin{array}{l}\text { Geva et al. }[95] \\
N=64 \\
\text { Age: } 21 \text { years }\end{array}$ & $\begin{array}{c}49 \pm \\
11\end{array}$ & $\begin{array}{c}5 \pm \\
9\end{array}$ & $\begin{array}{c}201 \pm \\
37\end{array}$ & $\begin{array}{c}123 \pm \\
25\end{array}$ & $\begin{array}{c}107 \pm \\
29\end{array}$ & $\begin{array}{c}68 \pm \\
24\end{array}$ & $47 \pm 8$ & $45 \pm 9$ & $\begin{array}{c}89 \pm \\
15\end{array}$ & $\begin{array}{c}94 \pm \\
17\end{array}$ & $58 \pm 8$ & $\begin{array}{c}57 \pm \\
7\end{array}$ & $\begin{array}{l}154(82- \\
200)\end{array}$ & $\begin{array}{l}150(80- \\
202)\end{array}$ & $\begin{array}{l}26.5(8- \\
47)\end{array}$ & $\begin{array}{l}27(10- \\
48)\end{array}$ & $\begin{array}{c}47 \% \text { grade } \\
\geq 11\end{array}$ & $\begin{array}{c}8 \% \text { grade } \\
\geq \| 1\end{array}$ \\
\hline
\end{tabular}


asymptomatic patients based on RV dilatation (RV/LV ratio $>2$ ) and abnormal exercise test results [94]. With an average preoperative RV end-diastolic volume of $142 \pm 43 \mathrm{ml} / \mathrm{m}^{2}$, RV end-systolic volume of $91 \pm 18$ $\mathrm{ml} / \mathrm{m}^{2}$, and RV ejection fraction $47 \pm 8 \%$, RV size and function was, on average, within normal limits one year after PVR. The authors, therefore, recommend PVR before RV end-diastolic volume exceeds $150 \mathrm{ml} / \mathrm{m}^{2}$. We analyzed pre-PVR predictors of normal post-PVR RV size (end-diastolic volume index $\leq 114 \mathrm{ml} / \mathrm{m}^{2}$ ) and function (ejection fraction $248 \%$ ) in 64 patients with severe chronic PR [95]. Independent predictors of normal RV size and function were pre-operative RV endsystolic volume index $<90 \mathrm{ml} / \mathrm{m}^{2}$ and QRS duration $<140 \mathrm{~ms}$.

Thus, the timing and indications for PVR after TOF repair must balance the benefits of elimination of RV volume load before irreversible dysfunction occurs and the disadvantages of a premature surgical or transcatheter procedure. As with any other medical procedure, the risks and benefits of the procedure must be weighed on a case-by-case basis, taking into account not only cardiac risk factors but also the risks associated with non-cardiac morbidities. With the above considerations in mind, the following summarizes the author's current recommendations for PVR in patients with repaired TOF or similar physiology. These recommendations will undoubtedly continue to evolve as new information becomes available and as valve technology and implantation methods continue to improve.

\section{Indications for Pulmonary Valve Replacement}

Indications for PVR in patients with repaired TOF or similar physiology with moderate or severe pulmonary regurgitation (regurgitation fraction $\geq 25 \%$ ):

I. Asymptomatic patient with two or more of the following criteria a. RV end-diastolic volume index $>150 \mathrm{ml} / \mathrm{m}^{2}$ or Z-score $>4$. In patients whose body surface area falls outside published normal data: $\mathrm{RV} / \mathrm{LV}$ end-diastolic volume ratio $>2$

b. RV end-systolic volume index $>80 \mathrm{ml} / \mathrm{m}^{2}$

c. RV ejection fraction $<47 \%$

d. LV ejection fraction $<55 \%$

e. Large RVOT aneurysm

f. QRS duration $>140 \mathrm{~ms}$

g. Sustained tachyarrhythmia related to right heart volume load

h. Other hemodynamically significant abnormalities:

$\circ$ RVOT obstruction with RV systolic pressure $\geq 2 / 3$ systemic

- Severe branch pulmonary artery stenosis $(<30 \%$

flow to affected lung) not amenable to transcatheter therapy

$\circ \geq$ Moderate tricuspid regurgitation
- Left-to-right shunt from residual atrial or ventricular septal defects with pulmonary-tosystemic flow ratio $\geq 1.5$

- Severe aortic regurgitation

- Severe aortic dilatation (diameter $\geq 5 \mathrm{~cm}$ )

II. Symptomatic Patients Symptoms and signs attributable to severe RV volume load documented by CMR or alternative imaging modality, fulfilling $\geq 1$ of the quantitative criteria detailed above. Examples of symptoms and signs include

a. Exercise intolerance not explained by extra-cardiac causes (e.g., lung disease, musculoskeletal anomalies, genetic anomalies, obesity), with documentation by exercise testing with metabolic cart $(\leq 70 \%$ predicted peak $\mathrm{VO}_{2}$ for age and gender not explained by chronotropic incompetence)

b. Signs and symptoms of heart failure (e.g., dyspnea with mild effort or at rest not explained by extracardiac causes, peripheral edema)

c. Syncope attributable to arrhythmia

III. Special considerations a. Due to higher risk of adverse clinical outcomes in patients who underwent TOF repair at age $\geq 3$ years [10], PVR may be considered if fulfill $\geq 1$ of the quantitative criteria in section I b. Women with severe PR and RV dilatation and/or dysfunction may be at risk for pregnancy-related complications [108]. Although no evidence is available to support benefit from pre-pregnancy PVR, the procedure may be considered if fulfilling $\geq 1$ of the quantitative criteria in section I

\section{Role of CMR}

Because it is not limited by acoustic window, not associated with exposure to ionizing radiation, and is noninvasive, CMR is ideally suited for longitudinal follow-up in patients with repaired TOF [109]. Since it provides accurate quantitative information on biventricular size and function, blood flow measurements, myocardial viability, and cardiovascular anatomy, in many centers CMR has become the preferred method of noninvasive imaging in patients with repaired TOF $[10,45,50,54,97,110-113]$. At Children's Hospital Boston, postoperative TOF is the most common diagnosis in patients referred for CMR, accounting for $\sim 23 \%$ of patients. However, comprehensive assessment of the patient with repaired TOF requires integration of information from clinical assessment (detailed history and physical examination) and laboratory investigations (ECG, Holter monitor, exercise test, and echocardiography). Computed tomography and radionuclear studies can be used when CMR is contraindicated or not available. Cardiac catheterization (with or without electrophysiological testing) is indicated in selected patients $[17,95,114]$. 


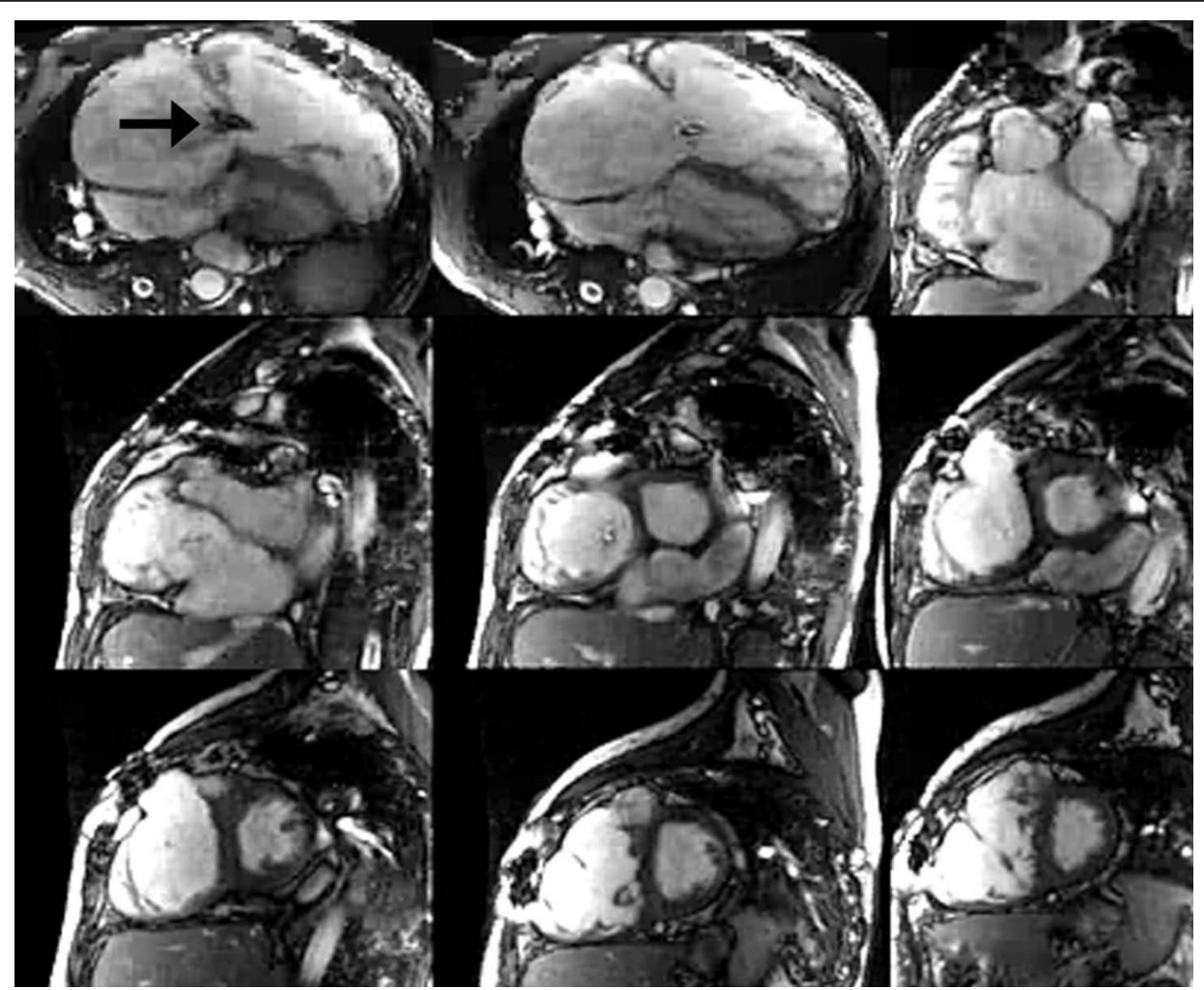

Figure 8 CMR imaging in a 37 year-old patient with repaired TOF, severe pulmonary regurgitation, moderate tricuspid regurgitation (arrow), and severe right ventricular dilatation (end-diastolic volume index $386 \mathrm{ml} / \mathrm{m}^{2}$ ) and dysfunction (ejection fraction 15\%). This patient who also exhibited severe heart failure symptoms had only modest decrease in RV size and no improvement in RV function after pulmonary valve replacement.

\section{Goals of CMR}

The goals of CMR in patients with repaired TOF include:

- Quantitative assessment of left and right ventricular volumes, mass, stroke volumes, and ejection fraction.

- Evaluation of regional wall motion abnormalities.

- Imaging the anatomy of the right ventricular outflow tract, pulmonary arteries, aorta, and aortopulmonary collaterals.

- Quantification of PR, tricuspid regurgitation, cardiac output, and pulmonary-to-systemic flow ratio.

- Assessment of myocardial viability with particular attention to scar tissue in the ventricular myocardium aside from sites of previous surgery (e.g., ventricular septal defect and RVOT patches).

\section{Study Protocol}

- The importance of careful attention to details of patient preparation and placement in the scanner cannot be overemphasized. Optimal placement of
ECG leads is paramount to quality gating. A peripheral intravenous cannula for injection of gadolinium-based contrast is placed in the following circumstances:

1. First CMR examination

2. >3 years since last late gadolinium enhancement (LGE) evaluation

3. Deterioration in clinical status

4. Regional or global ventricular function has worsened

Exceptions are made in young patients when placement of an intravenous cannula might result in loss of patient cooperation.

Imaging protocol

- Localizing images: ECG-gated steady-state free precession (SSFP) localizing imaging in the axial, coronal, and sagittal planes followed by real-time interactive sequences for identification of key imaging planes and structures targeted for additional sequences (e.g., ventricular long- and short-axis planes, short-axis of the proximal MPA for subsequent measurements of PR). 
- ECG-triggered, breath-hold cine SSFP in the following planes:

- LV 2-chamber (Figure 9)

- RV 2-chamber (Figure 10)

- 4-chamber (4 slices) (Figure 11)

- Ventricular short-axis (Figure 12). The latter is achieved by prescribing 12-14 equidistant slices (slice thickness 6-8 $\mathrm{mm}$; inter-slice space 0-2 $\mathrm{mm}$ ) covering the entire length of both ventricles. Particular attention is given to inclusion of the base of the RV and LV at end-diastole with addition of extra slices as needed for complete coverage.

- Oblique sagittal parallel to the RVOT and proximal MPA (Figure 13, Additional file 2).

- Parallel to the left ventricular outflow (LV 3-chamber view).

- Axial plane for imaging of the outflow tracts and branch pulmonary arteries (all first studies, optional thereafter).

Representative imaging parameters: echo time $1.7 \mathrm{~ms}$; repetition time $3.3 \mathrm{~ms}$; flip angle $60^{\circ}$; sensitivity encoding (SENSE) acceleration factor 2; field of view $260 \mathrm{~mm}$; matrix $160 \times 160$ reconstructed to $256 \times 256$; voxel size $1.6 \times 1.8 \times 6-8 \mathrm{~mm}$ reconstructed to $1.0 \times 1.0 \times 6-8$ $\mathrm{mm} ; 30$ reconstructed images per cardiac cycle.

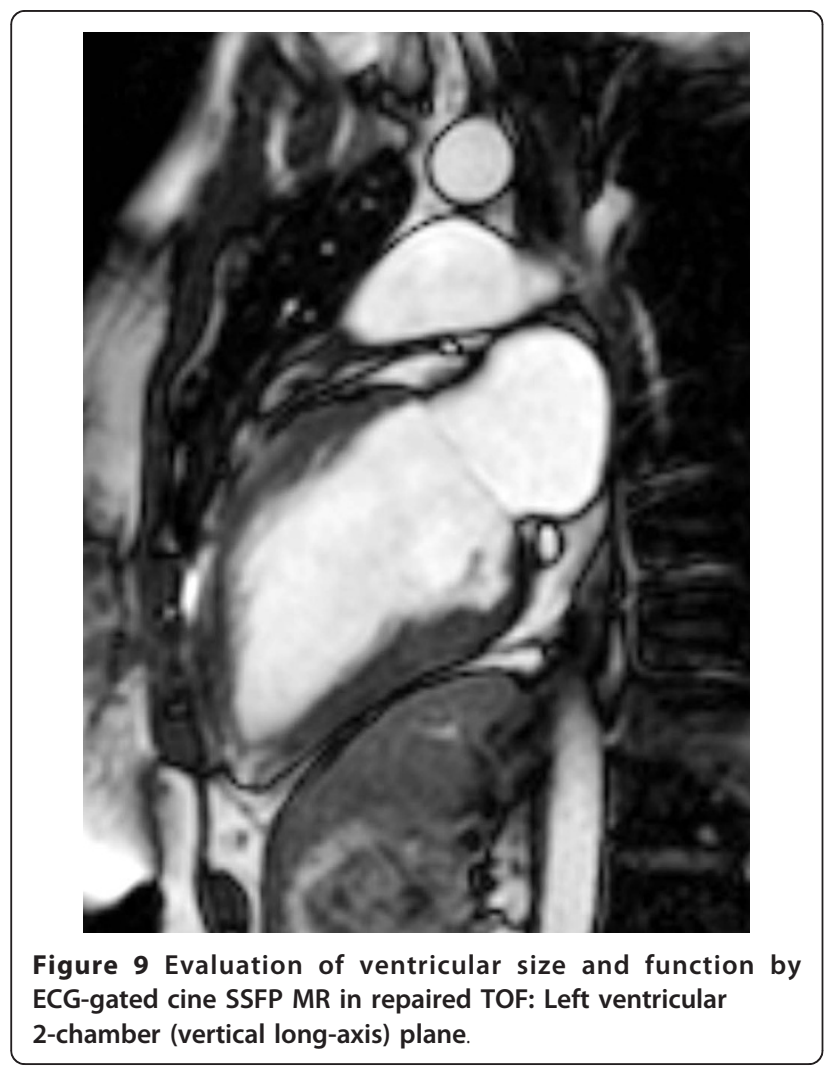

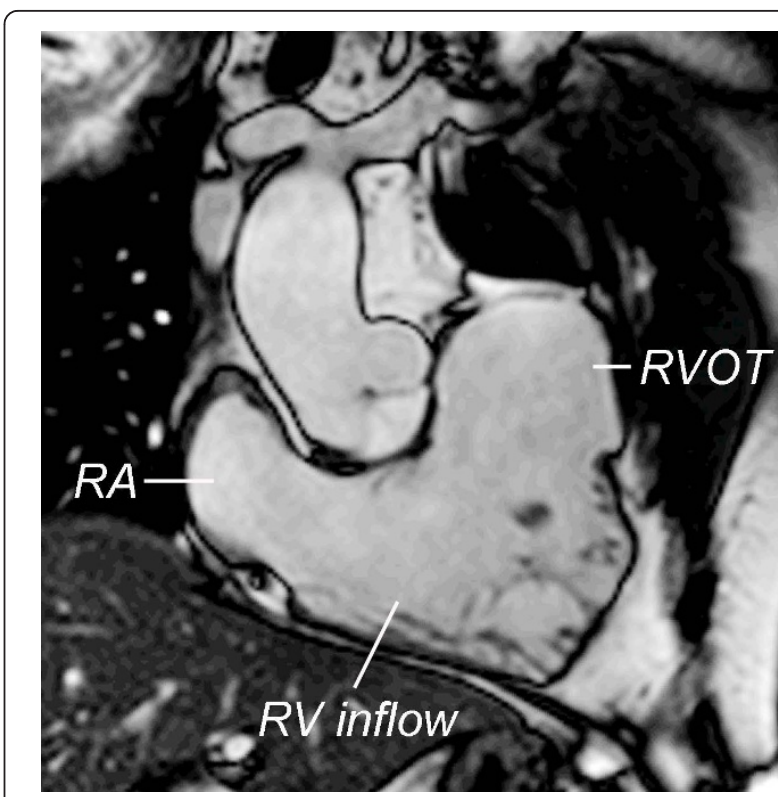

Figure 10 Evaluation of ventricular size and function by ECG-gated cine SSFP MR in repaired TOF: Right ventricular 2-chamber (vertical long-axis) plane. $\mathrm{RA}=$ right atrium; $\mathrm{RV}=$ right ventricle; RVOT = right ventricular outflow tract.

- Magnetic resonance angiogram (MRA): Nongated, breath-hold gadolinium-enhanced $(0.2 \mathrm{mmol} /$ $\mathrm{kg}$ gadopentetate dimeglumine) 3-dimensional MRA (all first studies, optional thereafter) (Figure 14). Representative imaging parameters: echo time 1.5 $\mathrm{ms}$; repetition time $4.5 \mathrm{~ms}$; flip angle $40^{\circ}$; voxel size $0.95 \times 1.06 \times 2.4 \mathrm{~mm}$ reconstructed to $0.68 \times 0.69 \times$ $1.2 \mathrm{~mm}$; number of acquisitions 2; SENSE acceleration factor 2; and acquisition time 20 s/acquisition.

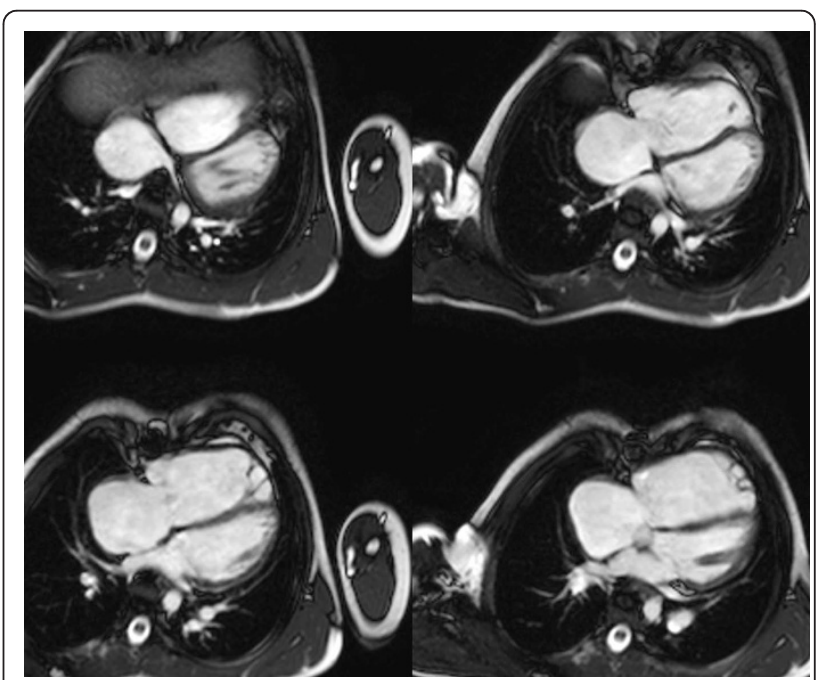

Figure 11 Evaluation of biventricular size and function by ECGgated cine SSFP MR in repaired TOF: 4-chamber (horizontal longaxis) plane. 


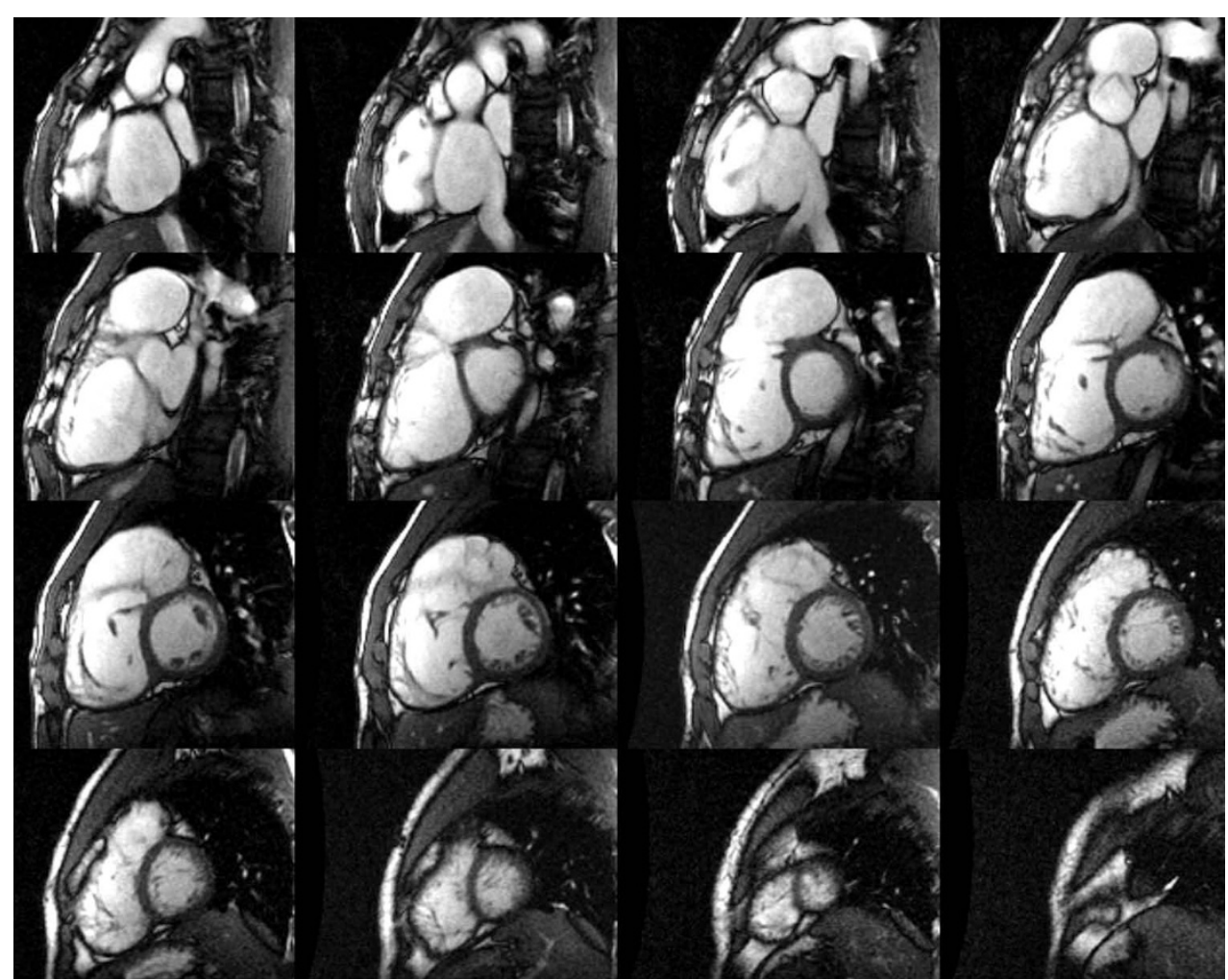

Figure 12 Evaluation of biventricular size and function by ECG-gated cine SSFP MR in repaired TOF: Ventricular short-axis. Note that 16 short-axis slices were required to fully cover the markedly dilated RV in this patient.

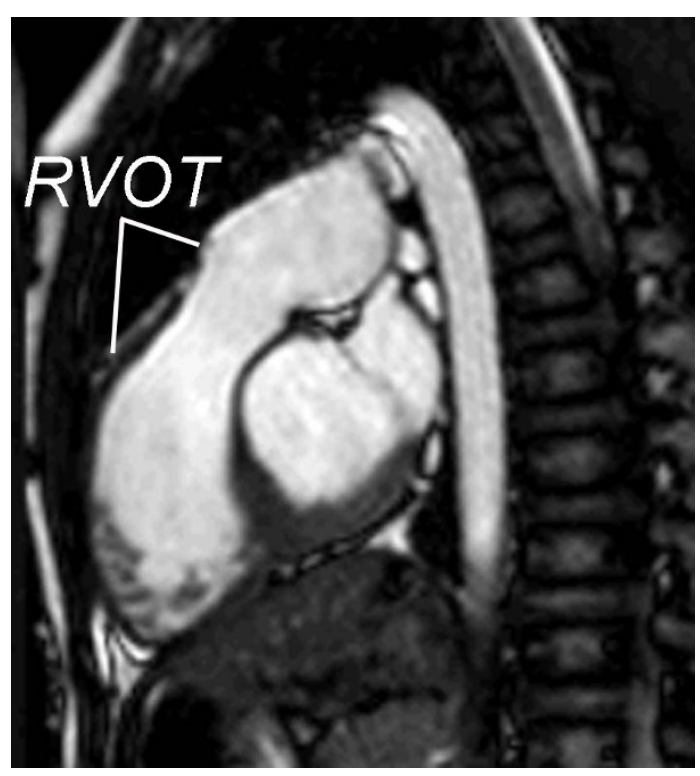

Figure 13 Evaluation of the right ventricular outflow tract (RVOT) long-axis by ECG-gated cine SSFP MR. Along with the RV 2-chamber plane (Figure 10), this view demonstrates patency of the RVOT and main pulmonary artery, presence or absence of pulmonary valve tissue, and wall motion abnormalities.

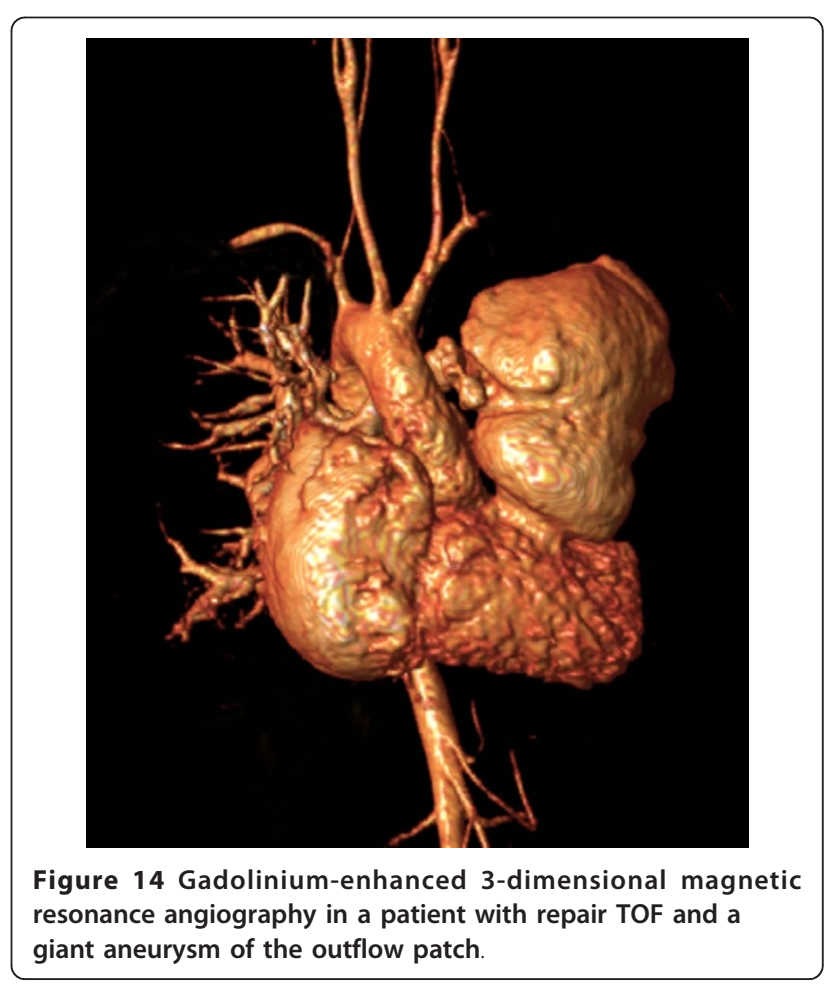


- Flow measurements: ECG-triggered, breathethrough cine phase contrast flow measurements in the MPA (Figures 15, 16, 17, Additional file 3), aorta, and atrioventricular valves. Representative imaging parameters: echo time $3.7 \mathrm{~ms}$; repetition time $5.9 \mathrm{~ms}$; flip angle $15^{\circ}$; SENSE factor 2 ; field of view $300 \mathrm{~mm}$; matrix $192 \times 192$; voxel size $1.56 \times$ $1.56 \times 6.0 \mathrm{~mm}$ reconstructed to $1.17 \times 1.17 \times 6.0$ $\mathrm{mm} ; 40$ reconstructed images per cardiac cycle.

- Late gadolinium enhancement (LGE): ECGtriggered, breath-hold, phase sensitive LGE imaging performed 10-20 minutes after contrast administration in the following planes: ventricular short-axis (Figure 18), LV 2-chamber, LV 3-chamber, RV 2-chamber, and 4-chamber. Areas suspected of LGE (e.g., the thin walled RVOT free wall) are imaged in orthogonal planes and with phase direction swapped to facilitate recognition of artifacts.

In addition to the above, the following imaging sequences are performed on a case-by-case basis:

- ECG-triggered, breath-hold cine SSFP in the shortaxis of the aortic root and ascending aorta (in patients with dilated aortic root and ascending aorta).

- ECG-triggered, breath-hold turbo (fast) spin echo sequence with blood suppression for imaging of the outflow tracts and branch pulmonary arteries in patients with image artifacts from metallic implants.

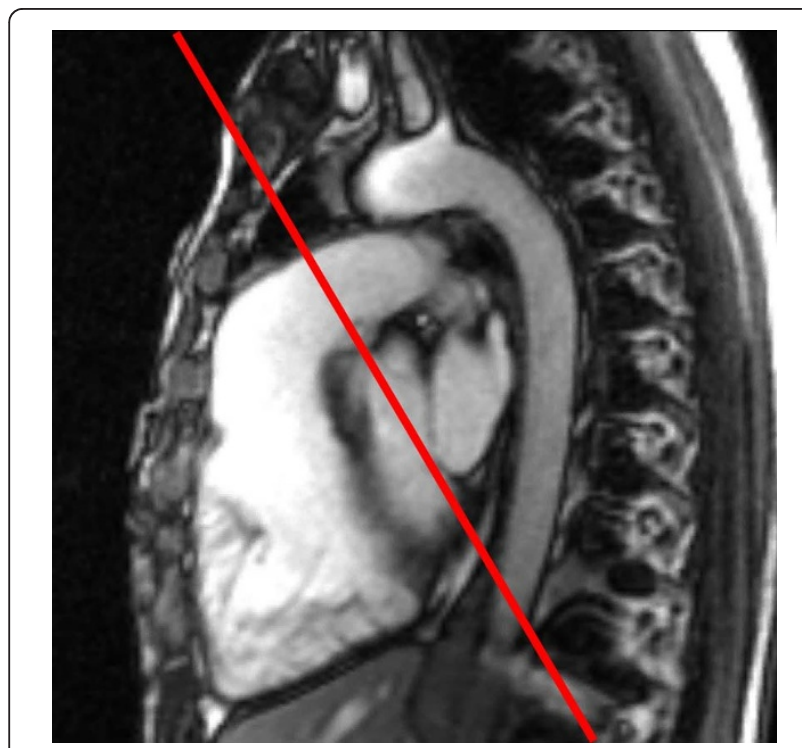

Figure 15 Evaluation of pulmonary regurgitation (PR) by ECG-gated cine phase contrast MR: The imaging plane is placed perpendicular to the long-axis of the main pulmonary artery (MPA)

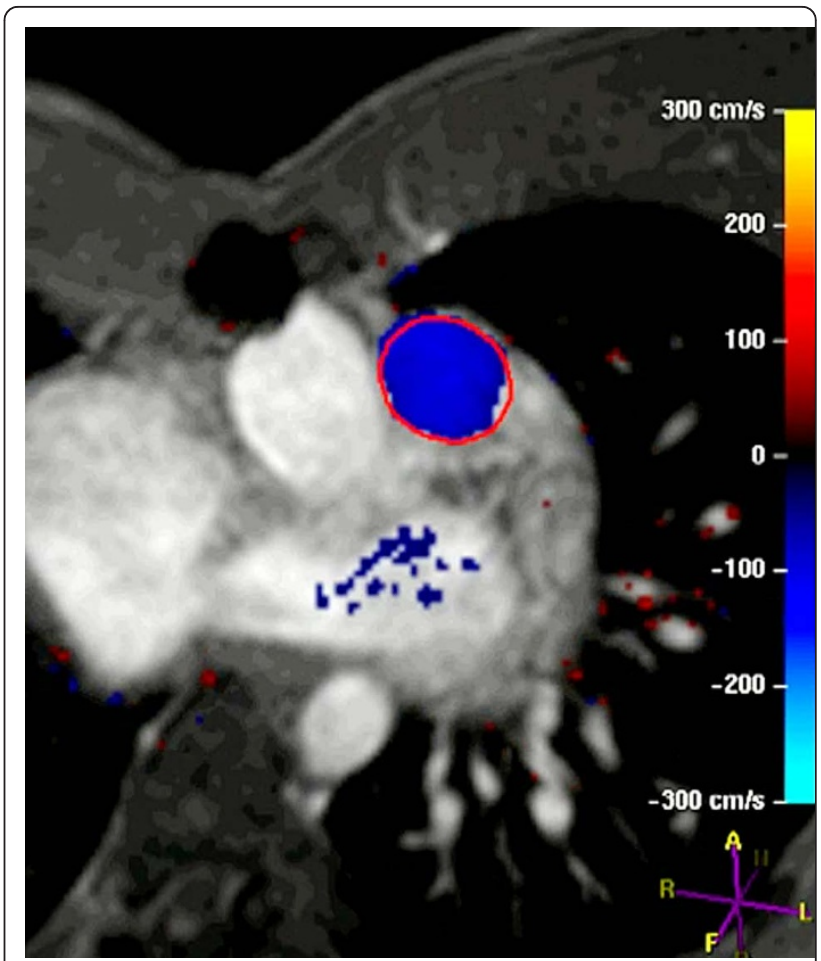

Figure 16 Evaluation of pulmonary regurgitation $(P R)$ by ECG-gated cine phase contrast MR: Color-coded flow map of the main pulmonary artery with the region of interest contour shown at peak systole.

- ECG-triggered, breathe-through cine phase contrast flow measurements in the branch pulmonary arteries (when branch pulmonary artery stenosis is identified).

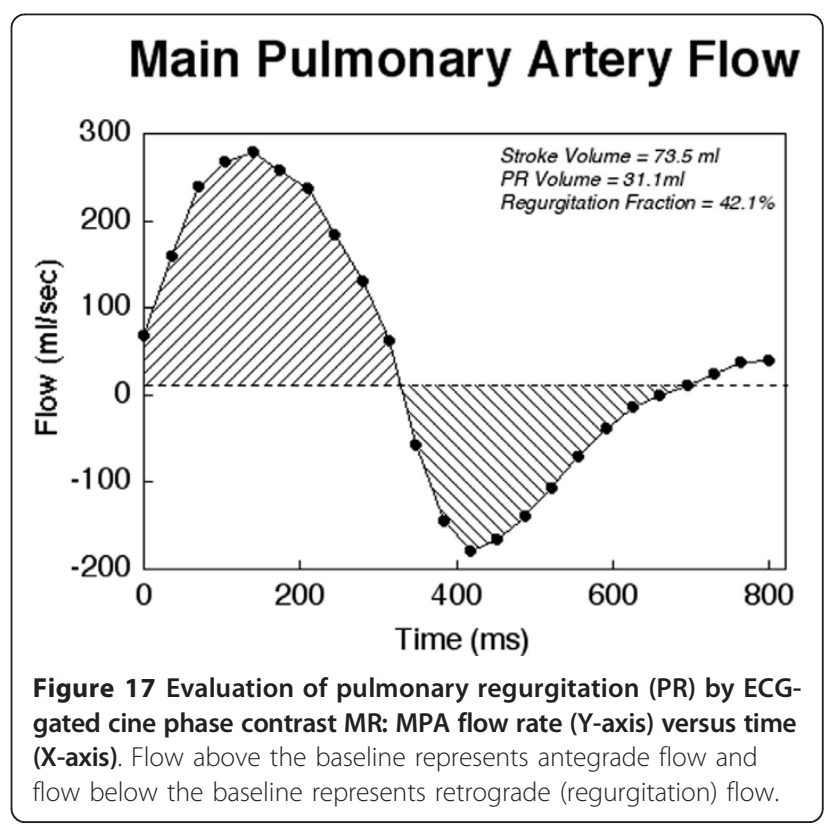




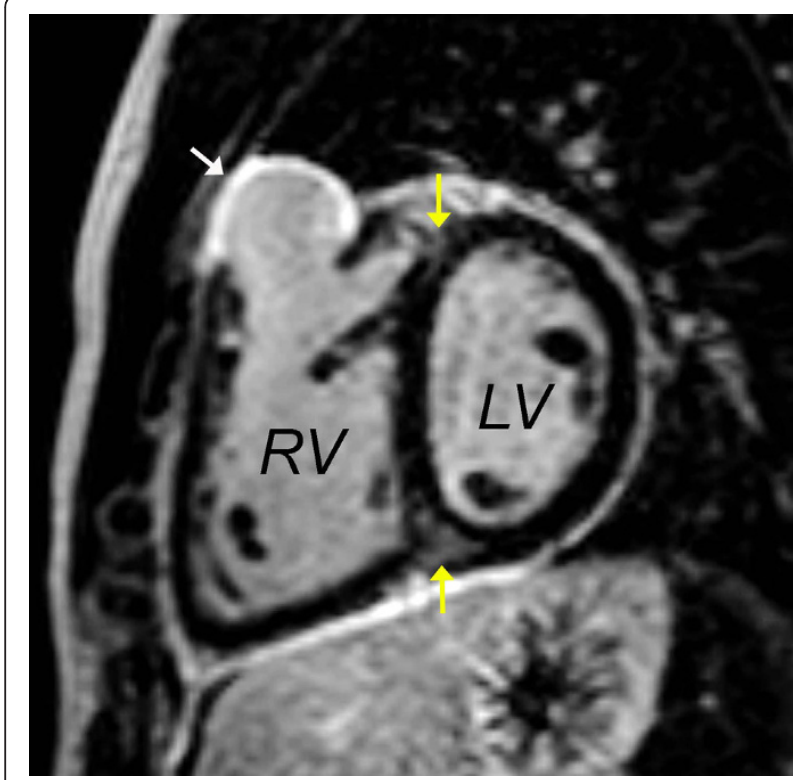

Figure 18 Late gadolinium enhancement imaging in the ventricular short-axis showing intense late hyperenhancement in the RVOT (white arrow) and weak hyperenhancement in the superior and inferior junctions between the interventricular septum and the free wall (yellow arrows). The former represents scar tissue and is associated with regional wall motion abnormalities. The latter is a commonly observed finding in patients with repaired TOF and its clinical importance is uncertain $[42,85]$.

- ECG-triggered, respiratory navigated, free breathing 3-dimensional isotropic SSFP for evaluation of the coronary arteries or as a substitute for contrast magnetic resonance angiography.

In a cooperative patient the above protocol is typically completed in 65-70 minutes.

\section{Report Template}

The importance of a structured report with an organized, comprehensive structure that addresses all key elements pertinent to clinical decision-making cannot be overemphasized. Key data reporting elements include:

- Anatomy of the RVOT and main and branch pulmonary arteries with emphasis on obstruction and/ or dilatation or aneurysm formation.

- Biventricular size and function (global and regional).

- Vessel dimensions: aortic root, ascending aorta, MPA, right and left pulmonary arteries; if abnormal (e.g., tricuspid regurgitation), diameters of the atrioventricular valve.

- Flow measurements:

- Ascending aorta, MPA, right and left pulmonary arteries
- Pulmonary valve regurgitation

- Other valve regurgitation

- Late gadolinium enhancement: presence, location, and extent.

- Associated anomalies: systemic and pulmonary veins, aortic arch sidedness and branching order.

An example of CMR report in a hypothetical patient with repaired TOF is available in Additional File 4.

\section{Offline analysis}

Quantification of right and left ventricular size and function and blood flow is performed using dedicated software available either from the manufacturers of MRI equipment or from third party vendors. Measurements of biventricular diastolic and systolic volumes and mass are performed on ECG-gated cine SSFP images, which provide a high contrast between the blood pool $(\mathrm{T} 2 / \mathrm{T} 1=$ $360 / 1200=0.3)$ and the myocardium $(\mathrm{T} 2 / \mathrm{T} 1=75 / 880=$ 0.085) [115]. Accurate determination of ventricular volume requires clear depiction of the blood-myocardial boundary. Adjustments of the image brightness and contrast on the computer screen can facilitate visualization of that boundary. By tracing the blood-endocardium boundary, the slice's blood pool volume is calculated as the product of its cross-sectional area and thickness (which is prescribed by the operator) (Figure 19). The left ventricular papillary muscles and the major trabeculations of the RV (e.g., septal band) are excluded from the blood pool and are considered part of the myocardium (Figure 19) $[46,116]$. Ventricular volume is then determined by summation of the volumes of all slices. The process can be repeated for each frame in the cardiac cycle to obtain a continuous time-volume loop or may be performed only on end-diastolic (maximal area) and end-systolic (minimal area) frames to calculate diastolic and systolic volumes. From this data one can calculate left and right ventricular stroke volumes and ejection fractions. Since the patient's heart rate at the time of image acquisition is known, one can calculate left and right ventricular outputs. Ventricular mass is calculated by tracing the epicardial borders and calculating the epicardial volume, subtracting the endocardial volume, and multiplying the resultant muscle volume by the specific gravity of the myocardium $\left(1.05 \mathrm{~g} / \mathrm{mm}^{3}\right)$.

Several approaches to measurements of biventricular size and function have been reported. In general, these can be divided into 2 broad categories: 1) methods that rely on summation of discs (Simpson's principle) [117]; and 2) methods that rely on modeling the chamber or extrapolation of sparse data [118-120]. In the first category each of the slices covering the ventricles is contoured at least once at end-diastole (largest volume) and at end-systole (smallest volume), requiring tracing 72 contours for biventricular volumes and mass. Some 


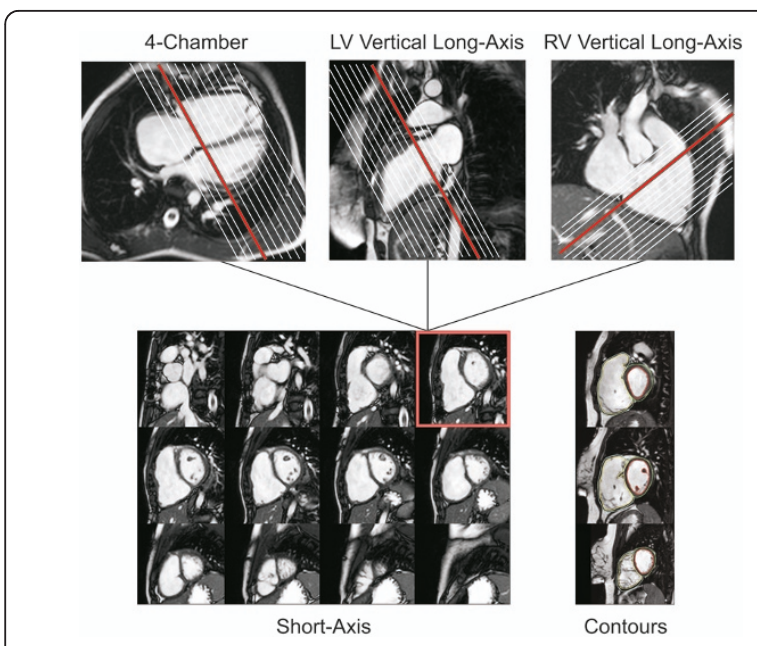

Figure $19 \mathrm{CMR}$ assessment of biventricular volumes and mass in repaired TOF. Cross-referencing between ventricular long- and short-axis imaging planes aids determining inclusion of basal slices in the ventricular volume analysis. When an operator selects a frame on the short-axis grid, that location is highlighted on the linked horizontal and vertical long axis images, allowing the operator to determine the location of the slab relative to the atrioventricular valves. Right lower panel: Examples of contour drawings on the left and right ventricular endocardial and epicardial boundaries at the base, mid-ventricular, and apical levels.

groups have advocated the use of images obtained in axial or oblique long-axis planes [121,122]. The major advantage of this approach, as compared with analysis based on short-axis images, is the ease of determining the planes of the mitral, tricuspid, and pulmonary valves. This advantage is likely responsible for the slightly higher reproducibility of measurements using older software [122]. However, this approach limits evaluation of ventricular mass because the epicardial and endocardial borders of the diaphragmatic wall are not clearly defined. Recent development of techniques that incorporate cross-references between long- and shortaxis images has greatly reduced the difficulty in determining valve plane on short-axis images (Figure 19) [123]. Moreover, most reports on normal values as well as the majority of the literature on ventricular size and function in repaired TOF and other congenital and acquired anomalies is based on analysis of short-axis images [116,124,125].

In the second category either a formula based on a geometrical model or extrapolation from sparse data are used to generate ventricular volumes [118-120]. The major advantage of this approach is shorter analysis time but it is disadvantaged by reduced accuracy.

In our center ventricular volumes and mass are measured from short-axis cine SSFP images [46]. Crossreferencing the short-axis images with left and right ventricular 2-chamber (vertical long-axis) and 4- chamber (horizontal long-axis) cine SSFP facilitates accurate determination of the atrioventricular and semilunar valves planes during systole and diastole [123]. In patients with repaired TOF particular attention should be paid when determining the end-diastolic and endsystolic phases of each ventricle. Given that conduction delay is nearly universal in this population, peak RV contraction typically lags after that of the LV by 1-3 cardiac phases (Figure 20). To optimize interstudy reproducibility in patients followed longitudinally, contours should be compared side-by-side with those from previous studies. Saving the contour files along with previous studies facilitates this comparison. On average, total analysis time is $\sim 30$ minutes and decreases with operator experience [123].

The technique for measuring blood flow is well established [109]. PR fraction is calculated as retrograde flow volume divided by antegrade flow volume in the proximal MPA using ECG-gated, free-breathing cine phase contrast sequence obtained in the short-axis of the proximal MPA (Figure 15 and 16) [46]. The operator should adjust the imaging plane to avoid impingement on the MPA by metallic artifacts from sternal wires and implants. In addition to the PR fraction, both the antegrade and retrograde flow volumes should be reported [126]. In the absence of a residual shunt, the net flow in the MPA and ascending aorta should be nearly identical. Similarly, in the absence of important tricuspid, mitral or aortic valve regurgitation or shunt, left and right ventricular stroke volume differential is primarily affected by PR and calculation of PR fraction by the 2 methods should be similar. In $15-20 \%$ of patients with repaired TOF, however, residual shunt(s) and tricuspid and/or aortic valve regurgitation are present, thus limiting the use of these comparisons [95].

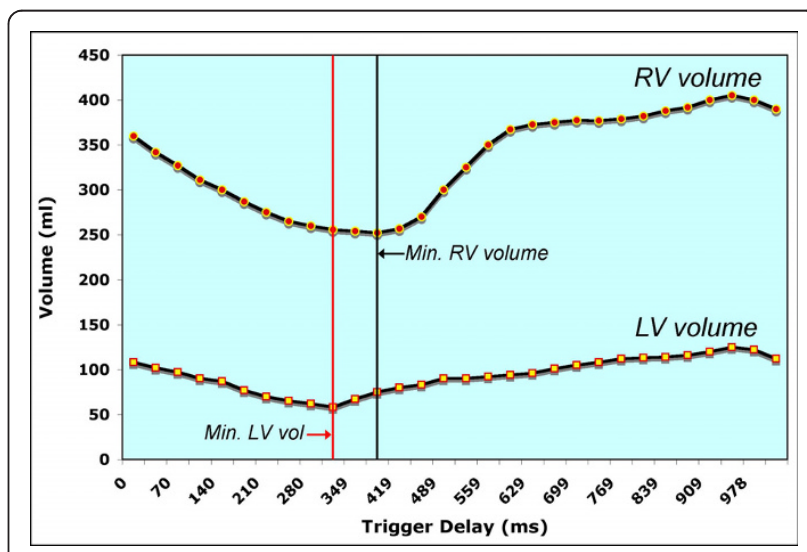

Figure 20 Plot of left and right ventricular volumes versus time throughout the cardiac cycle in a patient with repaired TOF. Note that minimal RV volume occurs $70 \mathrm{~ms}$ (2 cardiac phases) after minimal LV volume. 


\section{Reproducibility of CMR Measurements}

Most studies on the reproducibility of volumetric measurements by CMR have focused on the LV and those that included RV measurements were based on healthy volunteers or patients with acquired heart disease $[124,127]$. Few studies have addressed reproducibility of volumetric measurements by CMR in patients with repaired TOF [119,123,128]. Extrapolation of data from healthy volunteers or from adults with acquired heart disease to this group of patients may not be applicable because the RV is typically dilated and hypertrophied, the apical trabeculations are extensive, chamber geometry is abnormal with a prominent subtricuspid protrusion (the "shoulder" of the RV), the outflow patch is dyskinetic, the plane of the pulmonary valve can be unclear, and metallic artifacts from sternal wires or other implants can obscure parts of the chamber.

Mooij et al. analyzed the intra- and inter-observer variability of RV and LV size and function in 60 patients-20 with a normal RV, 20 with ASD or partially anomalous pulmonary venous connection, and 20 with repaired TOF [123]. In patients with repaired TOF intraclass correlations were 0.966 for RV end-diastolic volume, 0.932 for RV end-systolic volume, 0.817 for RV ejection fraction, and 0.831 for RV mass. Theses results are in agreement with those of Grothues et al. and Hudsmith et al. [124,129]. Bland-Altman analyses showed no systematic error in measurements related to the absolute value of the measures. The reproducibility of the measurements in patients with repaired TOF was not significantly different from that in patients with normal RV or with atrial septal defect. Moreover, the reproducibility of most RV measurements did not differ significantly from that of LV measurements. In practical terms, a difference of more than $34 \mathrm{ml} / \mathrm{m} 2$ (or $24 \%$ ) was less than $5 \%$ likely to be explained by interobserver variability.

\section{CMR in Clinical Decision Making}

CMR supports clinical decision making in patients with repaired TOF by providing comprehensive anatomic and functional information on postoperative cardiovascular abnormalities. Especially important in these patients is quantitative information on RV size, global and regional RV function, LV size and function, myocardial scar, RVOT aneurysm or obstruction, valve regurgitation (especially helpful when quantified), residual intracardiac shunts, and anatomic abnormalities of the pulmonary arteries and aorta. CMR is increasingly being incorporated into clinical surveillance protocols once patients with repaired TOF reach adolescence [109]. The combination of deteriorating echocardiographic windows, nearly universal ability to tolerate the CMR examination without sedation, and the comprehensive nature of the CMR data has contributed to its broad acceptance in this patient group. In addition to identifying anatomic and functional abnormalities (Table 1), CMR's ability to quantify chamber size and function and measure blood flow is especially helpful in clinical decision-making. For example, CMR can identify and characterize branch pulmonary artery stenosis (location, diameters, and length of the narrow segment) followed by flow measurements in the MPA and branch pulmonary arteries to quantify differential pulmonary flow. A relatively mild discrepancy in pulmonary blood flow (e.g., 40\% flow to one lung) in the absence of other indications for catheter or surgical intervention will likely lead the clinician to recommend expectant follow-up whereas severe discrepancy (e.g., $15 \%$ flow to one lung) will likely lead to intervention. Another example is identification of an atrial septal defect followed by measurement of the pulmonary-tosystemic flow ratio. A small shunt (e.g., pulmonary-tosystemic flow ratio of 1.3) in a patient with mild PR (e.g., $15 \%$ regurgitation fraction) and mild RV dilatation (e.g., $120 \mathrm{ml} / \mathrm{m}^{2}$ ) will likely lead the clinician to recommend expectant follow-up whereas the same shunt in a patient with moderate PR (e.g., 35\% regurgitation fraction) and $\mathrm{RV}$ dilatation (e.g., $145 \mathrm{ml} / \mathrm{m}^{2}$ ) will prompt a discussion about transcatheter device closure of the atrial septal defect versus PVR and atrial septal defect closure.

Perhaps the most critical role of CMR in supporting clinical decisions in patients with repaired TOF is determining when to replace or insert a pulmonary valve [114]. As indicated before, the decision to insert a pulmonary valve relies on clinical assessment of symptoms and signs attributable to the cardiovascular system and on measurements of PR, biventricular size and function, shunt ratio, and several morphologic criteria (e.g., RVOT aneurysm, branch pulmonary artery stenosis, severe aortic dilatation). Although some of the information necessary for clinical decision support for PVR can be obtained by other diagnostic modalities, CMR is best suited to reliably provide most or all necessary information $[97,109,114]$. For example, Doppler echocardiography can distinguish between mild and severe PR [130], 3-dimensional echocardiography has the potential to measure RV size and function [131], and tissue Doppler and speckle tracking can provide information on RV function [132]; RV size and function can also be measured by ECG-gated computed tomography and nuclear ventriculography $[63,133]$; and cardiac catheterization can provide information about pressure and shunt [134]. However, CMR provides the most comprehensive information in a single noninvasive examination without exposure to ionizing radiation [109]. Furthermore, the reproducibility of CMR in measuring key parameters necessary to support clinical decisions in repaired TOF has been published whereas similar data from other modalities in this group of patients is scant. Finally, 
most investigations on prognostic implications of the various parameters used to decide when to replace or insert a pulmonary valve are based on CMR data [14,15,93-96,98,135,136].

Although CMR has become the reference standard modality for follow-up of patients with repaired TOF, specific patient groups require a multimodality approach [137]. Table 4 summarizes several scenarios, in which a combination of diagnostic modalities is required to support clinical decisions after TOF repair.

\section{Future Directions}

Research efforts in TOF aim to address the many facets of the anomaly. Examples include elucidating the genetic and developmental etiologies of the anomaly, refining the initial surgical management to minimize late complications, defining markers of late adverse outcomes, refining the criteria for PVR to optimize late outcomes, and developing new tools to address the failing RV before and after PVR. CMR plays an important role in several of these research fronts. For example, CMR is used to evaluate the function of tissue-engineered semilunar valve implanted in the pulmonary position in sheep [138]. This and similar technologies have the potential to change the way TOF is repaired by allowing the use of myocardial patches and bioengineered valves derived from the patient's own cells to reconstruct the RVOT. CMR contributes to this line of research by allowing in-vivo evaluation of structure and function of valves and ventricles.

Another research front in TOF is management of the failing RV late after repair. It has recently been shown that "standard" RV remodeling does not improve RV function in this group of patients [95]. Our group has conducted a series of experiments designed to develop a computational modeling approach to determine the efficacy and suitability of the various reconstructive options for the RV $[139,140]$. Using patient-specific CMR data of biventricular structure, deformation, and flow, RV-LV computer models were constructed. These models included fluid-structure interactions, two-layer RV-LV structure, anisotropic material properties, fiber orientation, and active contraction. The models were designed to simulate blood flow, ventricular motion, and stressstrain distribution to evaluate the effect of different remodeling procedures on RV function, and to seek an optimal RV volume and patch design to improve postoperative outcomes (Figure 21, Additional file 5). This

Table 4 Examples of scenarios requiring a multimodality diagnostic approach

\begin{tabular}{|c|c|c|c|c|}
\hline & $\begin{array}{l}\text { Doppler } \\
\text { Echocardiography }\end{array}$ & Cardiac CT & $\begin{array}{l}\text { Nuclear } \\
\text { Scintigraphy }\end{array}$ & $\begin{array}{l}\text { Cardiac } \\
\text { Catheterization }\end{array}$ \\
\hline All patients & $\begin{array}{l}\text { - Predicted RV pressure by TR } \\
\text { jet velocity } \\
\text { - Valve function and } \\
\text { interrogation of atrial and } \\
\text { ventricular septa by color } \\
\text { Doppler }\end{array}$ & & & \\
\hline $\begin{array}{l}\text { RV hypertension with RVOT } \\
\text { obstruction or branch PA } \\
\text { stenosis }\end{array}$ & $\begin{array}{l}\text { Predicted RV pressure by TR jet } \\
\text { velocity }\end{array}$ & & & $\begin{array}{l}\text { Consider if (a) possible benefit from PA } \\
\text { balloon dilation and/or stent; or (b) } \\
\text { transcatheter PV implantation }\end{array}$ \\
\hline $\begin{array}{l}\text { RV hypertension without } \\
\text { RVOT obstruction or branch } \\
\text { PA stenosis }\end{array}$ & & & & $\begin{array}{l}\text { Assessment of peripheral branch PA } \\
\text { stenoses and pulmonary vascular } \\
\text { resistance }\end{array}$ \\
\hline $\begin{array}{l}\text { Branch PA stenosis without } \\
\text { reliable pulmonary flow } \\
\text { distribution by CMR }\end{array}$ & & & $\begin{array}{l}\text { Lung } \\
\text { perfusion } \\
\text { scan }\end{array}$ & \\
\hline $\begin{array}{l}\text { Branch PA stenosis with } \\
\leq 35 \% \text { flow to one lung }\end{array}$ & & & & $\begin{array}{l}\text { Consideration of balloon dilation with or } \\
\text { without stent placement }\end{array}$ \\
\hline $\begin{array}{l}\text { Contraindications to CMR or } \\
\text { large metallic artifacts }\end{array}$ & & $\begin{array}{l}\text { - Quantitative } \\
\text { evaluation of RV } \\
\text { size and } \\
\text { function } \\
\text { - Anatomy of } \\
\text { RVOT and } \\
\text { branch PAs }\end{array}$ & & \\
\hline Age $>40$ years & & & & Coronary angiography before PVR \\
\hline $\begin{array}{l}\text { Secundum ASD with } \\
\text { systemic } \mathrm{O}_{2} \text { saturation } \leq 92 \%\end{array}$ & & & & $\begin{array}{l}\text { Hemodynamic assessment } \pm \text { device } \\
\text { closure }\end{array}$ \\
\hline
\end{tabular}

$\mathrm{ASD}=$ atrial septal defect; $\mathrm{PA}=$ pulmonary artery; $\mathrm{PV}=$ pulmonary valve; $\mathrm{PVR}=$ pulmonary valve replacement; $\mathrm{RV}=$ right ventricle; RVOT = right ventricular outflow tract; $\mathrm{TR}=$ tricuspid regurgitation. 


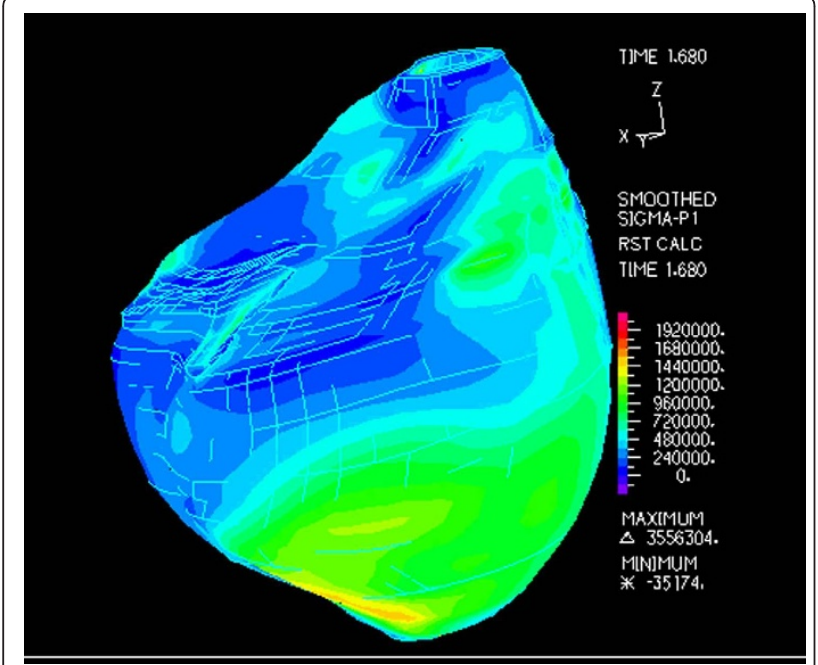

Figure 21 Computer model of right ventricular stress map based on CMR data of a patient with repaired TOF. This and similar models include fluid-structure interactions, two-layer RV-LV structure, anisotropic material properties, fiber orientation, and active contraction $[139,140]$. and similar research efforts may ultimately improve surgical planning by identifying optimal individual solutions to $\mathrm{RV}$ remodeling based on patient-specific, CMRderived computational models. Data from catheterization-CMR studies may provide more detailed information on RV mechanics (e.g., RV elastance or $E_{\max }$, ventricular-arterial coupling). Other advanced image analysis techniques such as CMR speckle tracking may overcome some of the limitations of RV tissue tagging and provide further insight into RV-LV mechanics in patients with repaired TOF (Figure 22) [141].

The most active clinical research efforts in repaired TOF continue to focus on refining the indications for PVR and developing better transcatheter and surgical techniques to address PR and other late complications. CMR plays a pivotal role in both fronts as the reference standard imaging tool for morphologic and functional assessments. As Table 3 demonstrates, past research efforts were dominated by small retrospective studies. Given that hard outcomes (e.g., death, ventricular tachycardia) after PVR are uncommon and it is unclear which surrogate outcomes properly reflect important

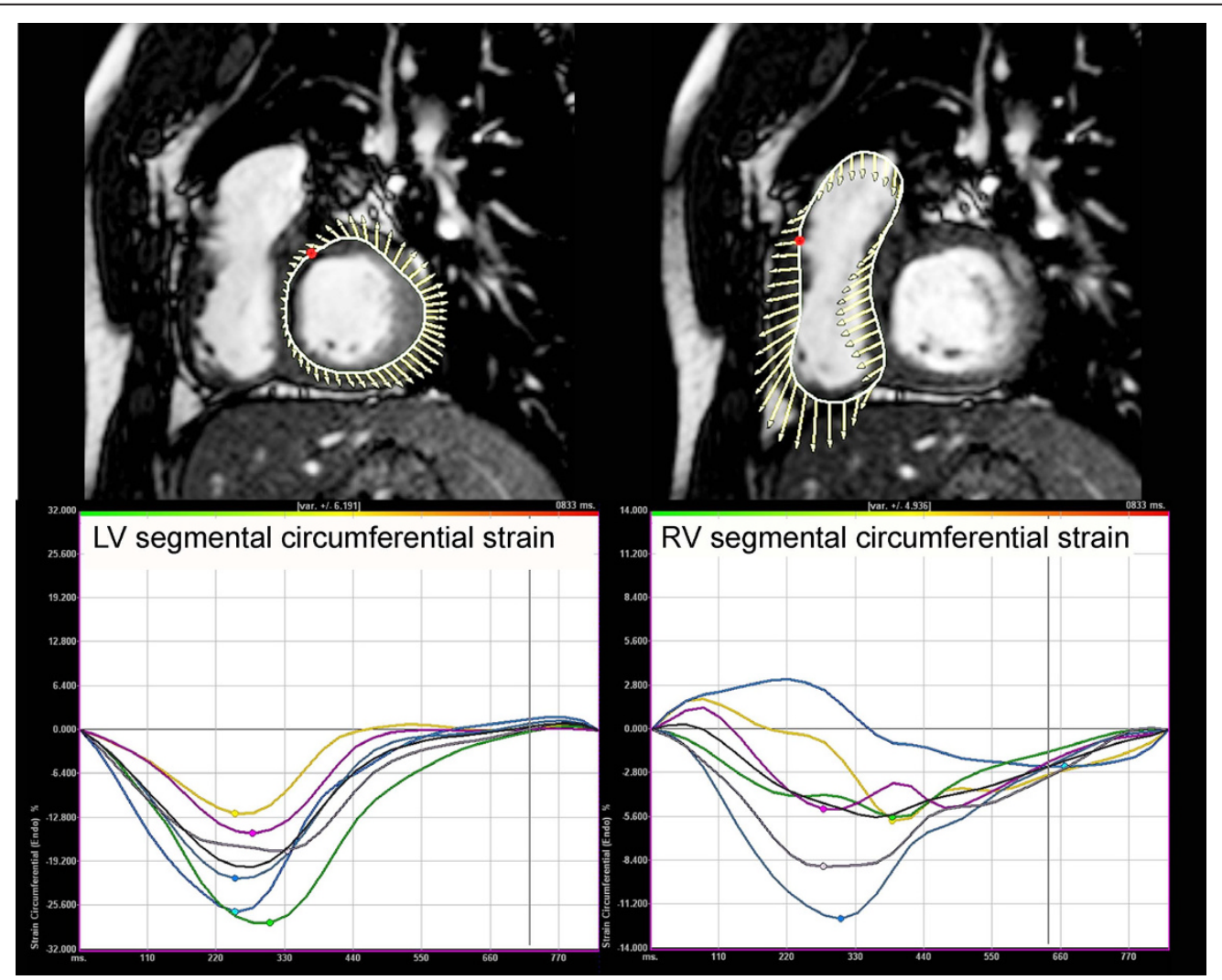

Figure 22 Tissue tracking of the ventricular myocardium ( $L V=$ left panel; RV = right panel) in a patient with repaired TOF. Analysis of circumferential strain is performed in the ventricular short-axis plane using a commercial tissue tracking software package and custom-built filters to modify the DICOM headers of the CMR datasets to allow them to be analyzed by the software package. The myocardium is divided into 6 segments and circumferential strain (Y-axis;\%) versus time (X-axis; milliseconds) is plotted for each segment. The time difference to peak circumferential strain-a measure of ventricular synchrony-measured 83 ms in the LV and 389 ms in the RV, reflecting RV dyssynchrony. 
outcomes, it is highly unlikely that single-center studies will provide meaningful answers. Undoubtedly, the next phase of clinical research aimed at identifying the optimal timing and method of restoring pulmonary valve competence will require analysis of large databases that include thousands patient years. This will require multicenter collaboration and, preferably, standardized prospectively acquired clinical and laboratory data, including CMR. Although a randomized clinical trial may appear to be an attractive research method to define the optimal timing of PVR, the design of such trial is challenging due to hurdles related to choice of outcomes, statistical power, and recruitment. However, once the state of knowledge in this area improves (e.g., identification of predictors of adverse outcomes after PVR and meaningful surrogate outcomes), it is conceivable that specific hypotheses can be formulated and then tested by a multicenter randomized trial. Undoubtedly, CMR will be an essential component of any such study.

\section{Conclusions}

The pathophysiology of repaired TOF is complex. Patients often tolerate the chronic volume load imposed by pulmonary regurgitation and, in some patients, by tricuspid regurgitation and residual intracardiac shunt (s), for many years. In other patients, the pathophysiology is further complicated by abnormalities in the pulmonary arterial tree. Over time, however, the risks of ventricular dysfunction, exercise intolerance, heart failure symptoms, arrhythmias, and death increase substantially. CMR has evolved to become a crucial diagnostic tool in this growing patient population. Key to optimal use of CMR in these patients is a comprehensive imaging protocol and implementation of steps to ensure consistency and reproducibility of measurements. Finally, CMR continues to play a key role in research efforts directed at improving outcomes of patients with tetralogy of Fallot.

\section{Additional material}

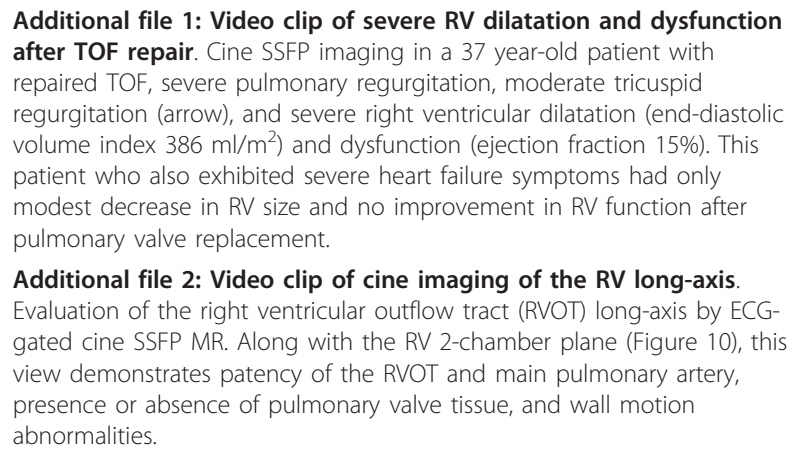

Additional file 3: Video clip of pulmonary regurgitation after TOF repair. Evaluation of pulmonary regurgitation (PR) by ECG-gated cine phase contrast MR. Antegrade flow from the RV to the MPA is encoded red and retrograde flow from the MPA to the RV (PR) is encoded blue.

Additional file 4: CMR report in repaired TOF. Example of CMR report in a hypothetical patient with repaired TOF

Additional file 5: Video clip of computer modeling of the RV after TOF repair. Computer model of right ventricular stress map based on CMR data of a patient with repaired TOF.

\section{Abbreviations}

CMR: cardiovascular magnetic resonance; LGE: late gadolinium enhancement; LV: left ventricle; PR: pulmonary regurgitation; PVR: pulmonary valve replacement; RV: right ventricle; RVOT: right ventricular outflow tract; TOF: tetralogy of Fallot.

\section{Acknowledgements and Funding}

This work was supported in part by the National Institutes of Health $(\mathrm{NIH} /$ NHLBI 1 R01 HL089269-01A2) and by the Higgins Family Noninvasive Cardiac Imaging Research Fund.

\section{Competing interests}

The author declares that they have no competing interests.

Received: 8 December 2010 Accepted: 20 January 2011 Published: 20 January 2011

\section{References}

1. Blalock A, Taussig HB: The surgical treatment of malformation of the heart in which there is pulmonary stenosis or pulmonary atresia. JAMA 1945, 128:189-202.

2. Lillehei CW, Cohen M, Warden HE, Varco RL: The direct-vision intracardiac correction of congenital anomalies by controlled cross circulation; results in thirty-two patients with ventricular septal defects, tetralogy of Fallot, and atrioventricularis communis defects. Surgery 1955, 38:11-29.

3. Lillehei CW, Cohen M, Warden HE, Read RC, Aust JB, Dewall RA, Varco RL: Direct vision intracardiac surgical correction of the tetralogy of Fallot, pentalogy of Fallot, and pulmonary atresia defects; report of first ten cases. Ann Surg 1955, 142:418-42.

4. Kirklin JW, Wallace RB, McGoon DC, DuShane JW: Early and late results after intracardiac repair of Tetralogy of Fallot. 5-Year review of 337 patients. Ann Surg 1965, 162:578-89.

5. Bacha EA, Scheule AM, Zurakowski D, Erickson LC, Hung J, Lang P, Mayer JE $\mathrm{Jr}$, del Nido PJ, Jonas RA: Long-term results after early primary repair of tetralogy of Fallot. J Thorac Cardiovasc Surg 2001, 122:154-61.

6. Parry AJ, McElhinney DB, Kung GC, Reddy VM, Brook MM, Hanley FL: Elective primary repair of acyanotic tetralogy of Fallot in early infancy: overall outcome and impact on the pulmonary valve. J Am Coll Cardiol 2000, 36:2279-83.

7. Pigula FA, Khalil PN, Mayer JE, del Nido PJ, Jonas RA: Repair of tetralogy of Fallot in neonates and young infants. Circulation 1999, 100:I1157-61.

8. Murphy JG, Gersh BJ, Mair DD, Fuster V, McGoon MD, Ilstrup DM, McGoon DC, Kirklin JW, Danielson GK: Long-term outcome in patients undergoing surgical repair of tetralogy of Fallot. N Engl J Med 1993, 329:593-9.

9. Nollert G, Fischlein T, Bouterwek S, Bohmer C, Klinner W, Reichart B: Longterm survival in patients with repair of tetralogy of Fallot: 36-year follow-up of 490 survivors of the first year after surgical repair. J Am Coll Cardiol 1997, 30:1374-83.

10. Geva T, Sandweiss BM, Gauvreau K, Lock JE, Powell AJ: Factors associated with impaired clinical status in long-term survivors of tetralogy of Fallot repair evaluated by magnetic resonance imaging. J Am Coll Cardiol 2004, 43:1068-74.

11. Gatzoulis MA, Walters J, McLaughlin PR, Merchant N, Webb GD, Liu P: Late arrhythmia in adults with the mustard procedure for transposition of great arteries: a surrogate marker for right ventricular dysfunction? Heart 2000, 84:409-15. 
12. Silka MJ, Hardy BG, Menashe VD, Morris CD: A population-based prospective evaluation of risk of sudden cardiac death after operation for common congenital heart defects. J Am Coll Cardiol 1998, 32:245-51.

13. Khairy P, Aboulhosn J, Gurvitz MZ, Opotowsky AR, Mongeon FP, Kay J, Valente AM, Earing MG, Lui G, Gersony DR, Cook S, Ting JG, Nickolaus MJ, Webb G, Landzberg MJ, Broberg CS: Arrhythmia burden in adults with surgically repaired tetralogy of Fallot: a multi-institutional study. Circulation 2010, 122:868-75.

14. Meijboom FJ, Roos-Hesselink JW, McGhie JS, Spitaels SE, van Domburg RT, Utens LM, Simoons ML, Bogers AJ: Consequences of a selective approach toward pulmonary valve replacement in adult patients with tetralogy of Fallot and pulmonary regurgitation. J Thorac Cardiovasc Surg 2008, 135:50-5.

15. Therrien J, Provost Y, Merchant N, Williams W, Colman J, Webb G: Optimal timing for pulmonary valve replacement in adults after tetralogy of Fallot repair. Am J Cardiol 2005, 95:779-82.

16. Buechel ER, Dave HH, Kellenberger CJ, Dodge-Khatami A, Pretre R, Berger F, Bauersfeld U: Remodelling of the right ventricle after early pulmonary valve replacement in children with repaired tetralogy of Fallot: assessment by cardiovascular magnetic resonance. Eur Heart J 2005, 26:2721-7.

17. Ammash NM, Dearani JA, Burkhart HM, Connolly HM: Pulmonary regurgitation after tetralogy of Fallot repair: clinical features, sequelae, and timing of pulmonary valve replacement. Congenit Heart Dis 2007, 2:386-403.

18. Kuehne T, Saeed M, Reddy G, Akbari H, Gleason K, Turner D, Teitel D, Moore $P$, Higgins CB: Sequential magnetic resonance monitoring of pulmonary flow with endovascular stents placed across the pulmonary valve in growing Swine. Circulation 2001, 104:2363-8.

19. Kuehne T, Saeed M, Gleason K, Turner D, Teitel D, Higgins CB, Moore P: Effects of pulmonary insufficiency on biventricular function in the developing heart of growing swine. Circulation 2003, 108:2007-13.

20. Siwek LG, Applebaum RE, Jones M, Clark RE: Acute control of pulmonary regurgitation with a balloon "valve". An experimental investigation. J Thorac Cardiovasc Surg 1985, 90:404-9.

21. Cloan SD: Hemodynamic measurements, in Echocardiography in pediatric and congenital heart disease: from fetus to adult.Edited by: Lai WW, Mertens LL, Cohen MS, Geva T. Wiley-Blackwell: Philadelphia; 2010:63-75.

22. Kilner PJ, Balossino R, Dubini G, Babu-Narayan SV, Taylor AM, Pennati G, Migliavacca F: Pulmonary regurgitation: the effects of varying pulmonary artery compliance, and of increased resistance proximal or distal to the compliance. Int I Cardiol 2009, 133:157-66.

23. Tverskaya MS, Mishnev OD, Raksha AP, Karpova W, Sukhoparova W, Izmailova NS, Virganskii AO, Kadyrova M, Abdulkerimova NZ: Comparative pathomorphological study of contractile myocardium under conditions of increased left and right ventricular afterload. Bull Exp Biol Med 2004, 138:616-20.

24. Gruver EJ, Morgan JP, Stambler BS, Gwathmey JK: Uniformity of calcium channel number and isometric contraction in human right and left ventricular myocardium. Basic Res Cardiol 1994, 89:139-48.

25. Chaliki HP, Mohty D, Avierinos JF, Scott CG, Schaff HV, Tajik AJ, EnriquezSarano M: Outcomes after aortic valve replacement in patients with severe aortic regurgitation and markedly reduced left ventricular function. Circulation 2002, 106:2687-93.

26. Tornos MP, Olona M, Permanyer-Miralda G, Evangelista A, Candell J, Padilla F, Soler Soler J: Heart failure after aortic valve replacement for aortic regurgitation: prospective 20-year study. Am Heart J 1998, 136:681-7.

27. Bekeredjian R, Grayburn PA: Valvular heart disease: aortic regurgitation. Circulation 2005, 112:125-34.

28. Sparrow P, Messroghli DR, Reid S, Ridgway JP, Bainbridge G, Sivananthan MU: Myocardial T1 mapping for detection of left ventricular myocardial fibrosis in chronic aortic regurgitation: pilot study. AJR Am J Roentgenol 2006, 187:W630-5.

29. Borer JS, Truter S, Herrold EM, Falcone DJ, Pena M, Carter JN, Dumlao TF, Lee JA, Supino PG: Myocardial fibrosis in chronic aortic regurgitation: molecular and cellular responses to volume overload. Circulation 2002, 105:1837-42.

30. Katz NM, Blackstone EH, Kirklin JW, Pacifico AD, Bargeron LM Jr: Late survival and symptoms after repair of tetralogy of Fallot. Circulation 1982, 65:403-10.
31. Shimazaki Y, Blackstone EH, Kirklin JW: The natural history of isolated congenital pulmonary valve incompetence: surgical implications. Thorac Cardiovasc Surg 1984, 32:257-9.

32. Roos-Hesselink JW, Meijboom FJ, Spitaels SE, van Domburg R, van Rijen EH, Utens EM, Bogers AJ, Simoons ML: Excellent survival and low incidence of arrhythmias, stroke and heart failure long-term after surgical ASD closure at young age. A prospective follow-up study of 21-33 years. Eur Heart J 2003, 24:190-7.

33. Pascotto M, Santoro G, Caso P, Cerrato F, Caso I, Caputo S, Bigazzi MC D'Andrea A, Russo MG, Calabro R: Global and regional left ventricular function in patients undergoing transcatheter closure of secundum atrial septal defect. Am J Cardiol 2005, 96:439-42.

34. Giardini A, Moore P, Brook M, Stratton V, Tacy T: Effect of transcatheter atrial septal defect closure in children on left ventricular diastolic function. Am J Cardiol 2005, 95:1255-7.

35. Salehian O, Horlick E, Schwerzmann M, Haberer K, McLaughlin P, Siu SC, Webb G, Therrien J: Improvements in cardiac form and function after transcatheter closure of secundum atrial septal defects. J Am Coll Cardiol 2005, 45:499-504.

36. Walker RE, Moran AM, Gauvreau K, Colan SD: Evidence of adverse ventricular interdependence in patients with atrial septal defects. Am J Cardiol 2004, 93:1374-7, A6

37. Celik S, Ozay B, Dagdeviren B, Gorgulu S, Yildirim A, Uslu N, Ketenci B, Eren $M$, Akgoz H, Demirtas M, Tezel T: Effect of patient age at surgical intervention on long-term right ventricular performance in atrial septal defect. Jpn Heart J 2004, 45:265-73.

38. Horvath KA, Burke RP, Collins JJ Jr, Cohn LH: Surgical treatment of adult atrial septal defect: early and long-term results. J Am Coll Cardiol 1992, 20:1156-9.

39. Jategaonkar S, Scholtz W, Schmidt H, Horstkotte D: Percutaneous closure of atrial septal defects: echocardiographic and functional results in patients older than 60 years. Circ Cardiovasc Interv 2009, 2:85-9.

40. Dell'Italia L: The right ventricle: anatomy, physiology, and clinical importance. Curr Probl Cardiol 1991, 16:653-720.

41. Geva T, Powell AJ, Crawford EC, Chung T, Colan SD: Evaluation of regional differences in right ventricular systolic function by acoustic quantification echocardiography and cine magnetic resonance imaging. Circulation 1998, 98:339-45.

42. Wald RM, Haber I, Wald R, Valente AM, Powell AJ, Geva T: Effects of regional dysfunction and late gadolinium enhancement on global right ventricular function and exercise capacity in patients with repaired tetralogy of Fallot. Circulation 2009, 119:1370-7.

43. Kiriazis $\mathrm{H}$, Gibbs $\mathrm{CL}$, Kotsanas $\mathrm{G}$, Young IR: Mechanical and energetic changes in short-term volume and pressure overload of rabbit heart. Heart Vessels 1992, 7:175-88.

44. Lytrivi ID, Ko HH, Srivastava S, Norton K, Goldman J, Parness IA, Lai WW, Nielsen JC: Regional differences in right ventricular systolic function as determined by cine magnetic resonance imaging after infundibulotomy. Am J Cardiol 2004, 94:970-3.

45. Davlouros PA, Kilner PJ, Hornung TS, Li W, Francis JM, Moon JC, Smith GC, Tat T, Pennell DJ, Gatzoulis MA: right ventricular function in adults with repaired tetralogy of Fallot assessed with cardiovascular magnetic resonance imaging: detrimental role of right ventricular outflow aneurysms or akinesia and adverse right-to-left ventricular interaction. $J$ Am Coll Cardiol 2002, 40:2044-52.

46. Samyn MM, Powell AJ, Garg R, Sena L, Geva T: Range of ventricular dimensions and function by steady-state free precession cine MRI in repaired tetralogy of Fallot: right ventricular outflow tract patch vs. conduit repair. J Magn Reson Imaging 2007, 26:934-40,

47. Knauth AL, Gauvreau K, Powell AJ, Landzberg MJ, Walsh EP, Lock JE, del Nido PJ, Geva T: Ventricular size and function assessed by cardiac MRI predict major adverse clinical outcomes late after tetralogy of Fallot repair. Heart 2008, 94:211-6.

48. Rebergen SA, Chin JG, Ottenkamp J, van der Wall EE, de Roos A: Pulmonary regurgitation in the late postoperative follow-up of tetralogy of Fallot. Volumetric quantitation by nuclear magnetic resonance velocity mapping. Circulation 1993, 88:2257-66

49. Helbing WA, Niezen RA, Le Cessie S, van der Geest RJ, Ottenkamp J, de Roos A: Right ventricular diastolic function in children with pulmonary regurgitation after repair of tetralogy of Fallot: volumetric evaluation by magnetic resonance velocity mapping. J Am Coll Cardiol 1996, 28:1827-35. 
50. Helbing WA, de Roos A: Clinical applications of cardiac magnetic resonance imaging after repair of tetralogy of Fallot. Pediatr Cardio/ 2000, 21:70-9.

51. Greenberg SB, Crisci KL, Koenig P, Robinson B, Anisman P, Russo P: Magnetic resonance imaging compared with echocardiography in the evaluation of pulmonary artery abnormalities in children with tetralogy of Fallot following palliative and corrective surgery. Pediatr Radiol 1997, 27:932-5.

52. Kurotobi S, Taniguchi K, Sano T, Naito H, Matsushita T, Kogaki S, Ichikawa $\mathrm{H}$, Ozono K: Determination of timing for reoperation in patients after right ventricular outflow reconstruction. Am J Cardiol 2005, 95:1344-50.

53. Babu-Narayan SV, Kilner PJ, Li W, Moon JC, Goktekin O, Davlouros PA, Khan M, Ho SY, Pennell DJ, Gatzoulis MA: Ventricular fibrosis suggested by cardiovascular magnetic resonance in adults with repaired tetralogy of fallot and its relationship to adverse markers of clinical outcome. Circulation 2006, 113:405-13.

54. van Straten A, Vliegen HW, Hazekamp MG, Lamb HJ, Ottenkamp J, Van der Wall EE, De Roos A: Right ventricular diastolic function before and after pulmonary valve replacement late after repair of tetralogy of Fallot assessed by cardiac magnetic resonance imaging. J Am Coll Cardiol 2003, 41:491.

55. Sandor GG, Patterson MW, Tipple M, Ashmore PG, Popov R: Left ventricular systolic and diastolic function after total correction of tetralogy of Fallot. Am J Cardiol 1987, 60:1148-51.

56. Eroglu AG, Sarioglu A, Sarioglu T: Right ventricular diastolic function after repair of tetralogy of Fallot: its relationship to the insertion of a 'transannular' patch. Cardiol Young 1999, 9:384-91.

57. Gatzoulis MA, Clark AL, Cullen S, Newman CG, Redington AN: Right ventricular diastolic function 15 to 35 years after repair of tetralogy of Fallot. Restrictive physiology predicts superior exercise performance. Circulation 1995, 91:1775-81.

58. van der Hulst AE, Westenberg JJ, Kroft $\sqcup$, Bax JJ, Blom NA, de Roos A Roest AA: Tetralogy of fallot: 3D velocity-encoded MR imaging for evaluation of right ventricular valve flow and diastolic function in patients after correction. Radiology 2010, 256:724-34

59. Ghai A, Silversides C, Harris L, Webb GD, Siu SC, Therrien J: Left ventricular dysfunction is a risk factor for sudden cardiac death in adults late after repair of tetralogy of fallot. J Am Coll Cardiol 2002, 40:1675-80.

60. Abd El Rahman MY, Hui W, Yigitbasi M, Dsebissowa F, Schubert S, Hetzer R, Lange PE, Abdul-Khaliq $\mathrm{H}$ : Detection of left ventricular asynchrony in patients with right bundle branch block after repair of tetralogy of Fallot using tissue-Doppler imaging-derived strain. J Am Coll Cardiol 2005, 45:915-21.

61. Kondo C, Nakazawa M, Kusakabe K, Momma K: Left ventricular dysfunction on exercise long-term after total repair of tetralogy of Fallot. Circulation 1995, 92: $11250-5$.

62. Hausdorf G, Hinrichs C, Nienaber CA, Schark C, Keck EW: Left ventricular contractile state after surgical correction of tetralogy of Fallot: risk factors for late left ventricular dysfunction. Pediatr Cardiol 1990, 11:61-8.

63. Therrien J, Siu SC, McLaughlin PR, Liu PP, Williams WG, Webb GD: Pulmonary valve replacement in adults late after repair of tetralogy of fallot: are we operating too late? J Am Coll Cardiol 2000, 36:1670-5.

64. Adams CW: Bernheim effect (produced by an interventricular septal aneurysm following septal infarction). Dis Chest 1966, 50:641-2.

65. Darsee JR, Mikolich JR, Walter PF, Schlant RC: Paradoxical rise in left ventricular filling pressure in the dog during positive end-expiratory pressure ventilation. A reversed Bernheim effect. Circ Res 1981, 49:1017-28.

66. Sanchez-Quintana D, Anderson RH, Ho SY: Ventricular myoarchitecture in tetralogy of Fallot. Heart 1996, 76:280-6.

67. Tzemos N, Harris L, Carasso S, Subira LD, Greutmann M, Provost Y Redington AN, Rakowski H, Siu SC, Silversides CK: Adverse left ventricular mechanics in adults with repaired tetralogy of Fallot. Am J Cardiol 2009 103:420-5.

68. Ooi A, Moorjani N, Baliulis G, Keeton BR, Salmon AP, Monro JL, Haw MP: Medium term outcome for infant repair in tetralogy of Fallot: Indicators for timing of surgery. Eur J Cardiothorac Surg 2006, 30:917-22.

69. Lee C, Lee CN, Kim SC, Lim C, Chang YH, Kang CH, Jo WM, Kim WH: Outcome after one-stage repair of tetralogy of Fallot. J Cardiovasc Surg (Torino) 2006, 47:65-70
70. Owen AR, Gatzoulis MA: Tetralogy of Fallot: Late outcome after repair and surgical implications. Semin Thorac Cardiovasc Surg Pediatr Card Surg Annu 2000, 3:216-226.

71. Alexiou C, Mahmoud H, Al-Khaddour A, Gnanapragasam J, Salmon AP, Keeton BR, Monro JL: Outcome after repair of tetralogy of Fallot in the first year of life. Ann Thorac Surg 2001, 71:494-500

72. Oechslin EN, Harrison DA, Harris L, Downar E, Webb GD, Siu SS, Williams WG: Reoperation in adults with repair of tetralogy of fallot: indications and outcomes. J Thorac Cardiovasc Surg 1999, 118:245-51.

73. Redington AN: Determinants of short- and long-term outcome in the surgical correction of tetralogy of Fallot. Curr Opin Pediatr 1993, 5:619-22.

74. Saul JP, Alexander ME: Preventing sudden death after repair of tetralogy of Fallot: complex therapy for complex patients. J Cardiovasc Electrophysiol 1999, 10:1271-87.

75. Kugler JD: Predicting sudden death in patients who have undergone tetralogy of fallot repair: is it really as simple as measuring ECG intervals? J Cardiovasc Electrophysiol 1998, 9:103-6.

76. Berul Cl, Hill SL, Geggel RL, Hijazi ZM, Marx GR, Rhodes J, Walsh KA, Fulton DR: Electrocardiographic markers of late sudden death risk in postoperative tetralogy of Fallot children. J Cardiovasc Electrophysio/ 1997, 8:1349-56.

77. Gatzoulis MA, Till JA, Somerville J, Redington AN: Mechanoelectrical interaction in tetralogy of Fallot. QRS prolongation relates to right ventricular size and predicts malignant ventricular arrhythmias and sudden death. Circulation 1995, 92:231-7.

78. Bricker JT: Risks, markers, and causes. Sudden death and tetralogy of Fallot. Circulation 1995, 92:158-9.

79. Khairy P, Landzberg MJ, Gatzoulis MA, Lucron H, Lambert J, Marcon F, Alexander ME, Walsh EP: Value of programmed ventricular stimulation after tetralogy of fallot repair: a multicenter study. Circulation 2004, 109:1994-2000

80. Gatzoulis MA, Balaji S, Webber SA, Siu SC, Hokanson JS, Poile C, Rosenthal M, Nakazawa M, Moller JH, Gillette PC, Webb GD, Redington AN: Risk factors for arrhythmia and sudden cardiac death late after repair of tetralogy of Fallot: a multicentre study. Lancet 2000, 356:975-81.

81. Harrison DA, Harris L, Siu SC, MacLoghlin CJ, Connelly MS, Webb GD, Downar E, McLaughlin PR, Williams WG: Sustained ventricular tachycardia in adult patients late after repair of tetralogy of Fallot. J Am Coll Cardiol 1997, 30:1368-73.

82. Niezen RA, Helbing WA, van der Wall EE, van der Geest RJ, Rebergen SA, de Roos A: Biventricular systolic function and mass studied with MR imaging in children with pulmonary regurgitation after repair for tetralogy of Fallot. Radiology 1996, 201:135-40.

83. Abd El Rahman MY, Abdul-Khaliq H, Vogel M, Alexi-Meskishvili V, Gutberlet M, Lange PE: Relation between right ventricular enlargement, QRS duration, and right ventricular function in patients with tetralogy of Fallot and pulmonary regurgitation after surgical repair. Heart 2000 84:416-20

84. Doughan AR, McConnell ME, Lyle TA, Book WM: Effects of pulmonary valve replacement on QRS duration and right ventricular cavity size late after repair of right ventricular outflow tract obstruction. Am J Cardiol 2005, 95:1511-4.

85. Babu-Narayan SV, Goktekin O, Moon JC, Broberg CS, Pantely GA, Pennell DJ, Gatzoulis MA, Kilner PJ: Late gadolinium enhancement cardiovascular magnetic resonance of the systemic right ventricle in adults with previous atrial redirection surgery for transposition of the great arteries. Circulation 2005, 111:2091-8.

86. Therrien J, Siu SC, Harris L, Dore A, Niwa K, Janousek J, Williams WG, Webb G, Gatzoulis MA: Impact of pulmonary valve replacement on arrhythmia propensity late after repair of tetralogy of Fallot. Circulation 2001, 103:2489-94

87. Discigil B, Dearani JA, Puga FJ, Schaff HV, Hagler DJ, Warnes CA, Danielson GK: Late pulmonary valve replacement after repair of tetralogy of Fallot. J Thorac Cardiovasc Surg 2001, 121:344-51.

88. Harrild DM, Berul Cl, Cecchin F, Geva T, Gauvreau K, Pigula F, Walsh EP. Pulmonary valve replacement in tetralogy of Fallot: impact on survival and ventricular tachycardia. Circulation 2009, 119:445-51.

89. Caldarone CA, McCrindle BW, Van Arsdell GS, Coles JG, Webb G, Freedom RM, Williams WG: Independent factors associated with longevity of prosthetic pulmonary valves and valved conduits. J Thorac Cardiovasc Surg 2000, 120:1022-30, discussion 1031 
90. Bonhoeffer P, Boudjemline Y, Qureshi SA, Le Bidois J, Iserin L, Acar P, Merckx J, Kachaner J, Sidi D: Percutaneous insertion of the pulmonary valve. J Am Coll Cardiol 2002, 39:1664-9.

91. McElhinney DB, Hellenbrand WE, Zahn EM, Jones TK, Cheatham JP, Lock JE, Vincent JA: Short- and medium-term outcomes after transcatheter pulmonary valve placement in the expanded multicenter US melody valve trial. Circulation 2010, 122:507-16.

92. Nordmeyer J, Lurz P, Tsang VT, Coats L, Walker F, Taylor AM, Khambadkone S, de Leval MR, Bonhoeffer P: Effective transcatheter valve implantation after pulmonary homograft failure: a new perspective on the Ross operation. J Thorac Cardiovasc Surg 2009, 138:84-8.

93. Oosterhof T, van Straten A, Vliegen HW, Meijboom FJ, van Dijk AP, Spijkerboer AM, Bouma BJ, Zwinderman AH, Hazekamp MG, de Roos A, Mulder BJ: Preoperative thresholds for pulmonary valve replacement in patients with corrected tetralogy of Fallot using cardiovascular magnetic resonance. Circulation 2007, 116:545-51.

94. Frigiola A, Tsang V, Bull C, Coats L, Khambadkone S, Derrick G, Mist B, Walker F, van Doorn C, Bonhoeffer $\mathrm{P}$, Taylor AM: Biventricular response after pulmonary valve replacement for right ventricular outflow tract dysfunction: is age a predictor of outcome? Circulation 2008, 118:S182-90.

95. Geva T, Gauvreau K, Powell AJ, Cecchin F, Rhodes J, Geva J, del Nido P: Randomized trial of pulmonary valve replacement with and without right ventricular remodeling surgery. Circulation 2010, 122:S201-8.

96. Cheung EW, Wong WH, Cheung YF: Meta-analysis of pulmonary valve replacement after operative repair of tetralogy of fallot. Am J Cardiol 2010, 106:552-7.

97. Vliegen HW, Van Straten A, De Roos A, Roest AA, Schoof PH, Zwinderman AH, Ottenkamp J, Van Der Wall EE, Hazekamp MG: Magnetic resonance imaging to assess the hemodynamic effects of pulmonary valve replacement in adults late after repair of tetralogy of fallot. Circulation 2002, 106:1703-7.

98. Henkens IR, van Straten A, Schalij MJ, Hazekamp MG, de Roos A, van der Wall EE, Vliegen HW: Predicting outcome of pulmonary valve replacement in adult tetralogy of Fallot patients. Ann Thorac Surg 2007, 83:907-11.

99. Gengsakul A, Harris L, Bradley TJ, Webb GD, Williams WG, Siu SC, Merchant N, McCrindle BW: The impact of pulmonary valve replacement after tetralogy of Fallot repair: a matched comparison. Eur J Cardiothorac Surg 2007, 32:462-8.

100. Dave HH, Buechel ER, Dodge-Khatami A, Kadner A, Rousson V, Bauersfeld U, Pretre R: Early insertion of a pulmonary valve for chronic regurgitation helps restoration of ventricular dimensions. Ann Thorac Surg 2005, 80:1615-20, discussion 1620-1

101. Yemets IM, Williams WG, Webb GD, Harrison DA, McLaughlin PR, Trusler GA, Coles JG, Rebeyka IM, Freedom RM: Pulmonary valve replacement late after repair of tetralogy of Fallot. Ann Thorac Surg 1997, 64:526-30.

102. Eyskens B, Reybrouck T, Bogaert J, Dymarkowsky S, Daenen W, Dumoulin M, Gewillig M: Homograft insertion for pulmonary regurgitation after repair of tetralogy of fallot improves cardiorespiratory exercise performance. Am J Cardiol 2000, 85:221-5.

103. van Straten A, Vliegen HW, Hazekamp MG, de Roos A: Right ventricular function late after total repair of tetralogy of Fallot. Eur Radio/ 2005, 15:702-7

104. Oosterhof T, Mulder BJ, Vliegen HW, de Roos A: Corrected tetralogy of Fallot: delayed enhancement in right ventricular outflow tract. Radiology 2005, 237:868-71.

105. Warner KG, O'Brien PK, Rhodes J, Kaur A, Robinson DA, Payne DD: Expanding the indications for pulmonary valve replacement after repair of tetralogy of fallot. Ann Thorac Surg 2003, 76:1066-71, discussion 1071-2.

106. Lurz P, Giardini A, Taylor AM, Nordmeyer J, Muthurangu V, Odendaal D, Mist B, Khambadkone S, Schievano S, Bonhoeffer P, Derrick G: Effect of altering pathologic right ventricular loading conditions by percutaneous pulmonary valve implantation on exercise capacity. Am J Cardiol 2010, 105:721-6.

107. Graham TP Jr, Bernard Y, Arbogast P, Thapa S, Cetta F, Child J, Chugh R, Davidson W, Hurwitz R, Kay J, Sanders S, Schaufelberger M: Outcome of pulmonary valve replacements in adults after tetralogy repair: a multiinstitutional study. Congenit Heart Dis 2008, 3:162-7.

108. Khairy P, Ouyang DW, Fernandes SM, Lee-Parritz A, Economy KE, Landzberg MJ: Pregnancy outcomes in women with congenital heart disease. Circulation 2006, 113:517-24.

109. Kilner PJ, Geva T, Kaemmerer H, Trindade PT, Schwitter J, Webb GD: Recommendations for cardiovascular magnetic resonance in adults with congenital heart disease from the respective working groups of the European Society of Cardiology. Eur Heart J 2010, 31:794-805.

110. Kang IS, Redington AN, Benson LN, Macgowan C, Valsangiacomo ER, Roman K, Kellenberger CJ, Yoo SJ: Differential regurgitation in branch pulmonary arteries after repair of tetralogy of Fallot: a phase-contrast cine magnetic resonance study. Circulation 2003, 107:2938-43.

111. Babu-Narayan SV, Gatzoulis MA: Management of Adults with Operated Tetralogy of Fallot. Curr Treat Options Cardiovasc Med 2003, 5:389-398.

112. Choe YH, Kang IS, Park SW, Lee HJ: MR imaging of congenital heart diseases in adolescents and adults. Korean J Radiol 2001, 2:121-31.

113. de Roos A, Roest AA: Evaluation of congenital heart disease by magnetic resonance imaging. Eur Radiol 2000, 10:2-6.

114. Geva T: Indications and timing of pulmonary valve replacement after tetralogy of fallot repair. Semin Thorac Cardiovasc Surg Pediatr Card Surg Annu 2006, 11-22.

115. Carr JC, Simonetti O, Bundy J, Li D, Pereles S, Finn JP: Cine MR angiography of the heart with segmented true fast imaging with steady-state precession. Radiology 2001, 219:828-34

116. Alfakih K, Plein S, Thiele H, Jones T, Ridgway JP, Sivananthan MU: Normal human left and right ventricular dimensions for MRI as assessed by turbo gradient echo and steady-state free precession imaging sequences. J Magn Reson Imaging 2003, 17:323-9.

117. Alfakih K, Thiele H, Plein S, Bainbridge GJ, Ridgway JP, Sivananthan MU: Comparison of right ventricular volume measurement between segmented k-space gradient-echo and steady-state free precession magnetic resonance imaging. J Magn Reson Imaging 2002, 16:253-8.

118. Hergan K, Schuster A, Fruhwald J, Mair M, Burger R, Topker M: Comparison of left and right ventricular volume measurement using the Simpson's method and the area length method. Eur J Radiol 2008, 65:270-8.

119. Sheehan FH, Kilner PJ, Sahn DJ, Vick GW, Stout KK, Ge S, Helbing WA, Lewin M, Shurman AJ, Buechel EV, Litt HI, Waiss MP: Accuracy of knowledge-based reconstruction for measurement of right ventricular volume and function in patients with tetralogy of Fallot. Am J Cardiol 2010, 105:993-9.

120. Moroseos T, Mitsumori L, Kerwin WS, Sahn DJ, Helbing WA, Kilner PJ, Shurman A, Litt H, Sheehan FH: Comparison of Simpson's method and three-dimensional reconstruction for measurement of right ventricular volume in patients with complete or corrected transposition of the great arteries. Am J Cardiol 2010, 105:1603-9.

121. Strugnell WE, Slaughter RE, Riley RA, Trotter AJ, Bartlett H: Modified RV short axis series-a new method for cardiac MRI measurement of right ventricular volumes. J Cardiovasc Magn Reson 2005, 7:769-74.

122. Alfakih K, Plein S, Bloomer $\mathrm{T}$, Jones $\mathrm{T}$, Ridgway J, Sivananthan $\mathrm{M}$ : Comparison of right ventricular volume measurements between axial and short axis orientation using steady-state free precession magnetic resonance imaging. J Magn Reson Imaging 2003, 18:25-32.

123. Mooij CF, de Wit CJ, Graham DA, Powell AJ, Geva T: Reproducibility of MRI measurements of right ventricular size and function in patients with normal and dilated ventricles. J Magn Reson Imaging 2008, 28:67-73.

124. Hudsmith LE, Petersen SE, Francis JM, Robson MD, Neubauer S: Normal human left and right ventricular and left atrial dimensions using steady state free precession magnetic resonance imaging. J Cardiovasc Magn Reson 2005, 7:775-82

125. Buechel EV, Kaiser T, Jackson C, Schmitz A, Kellenberger CJ: Normal rightand left ventricular volumes and myocardial mass in children measured by steady state free precession cardiovascular magnetic resonance. $J$ Cardiovasc Magn Reson 2009, 11:19.

126. Wald RM, Redington AN, Pereira A, Provost YL, Paul NS, Oechslin EN, Silversides CK: Refining the assessment of pulmonary regurgitation in adults after tetralogy of Fallot repair: should we be measuring regurgitant fraction or regurgitant volume? Eur Heart J 2009, 30:356-61.

127. Karamitsos T, Hudsmith L, Selvanayagama J, Neubauer S, Francis J: Operator induced variability in left ventricular measurements with cardiovascular magnetic resonance is improved after training. J Cardiovasc Mag Reson 2007, 9:777-783

128. Beygui F, Furber A, Delepine S, Helft G, Metzger JP, Geslin P, Le Jeune JJ: Routine breath-hold gradient echo MRI-derived right ventricular mass, volumes and function: accuracy, reproducibility and coherence study. Int J Cardiovasc Imaging 2004, 20:509-16. 
129. Grothues F, Moon JC, Bellenger NG, Smith GS, Klein HU, Pennell DJ: Interstudy reproducibility of right ventricular volumes, function, and mass with cardiovascular magnetic resonance. Am Heart J 2004, 147:218-23.

130. Renella P, Aboulhosn J, Lohan DG, Jonnala P, Finn JP, Satou GM, Williams RJ, Child JS: Two-dimensional and Doppler echocardiography reliably predict severe pulmonary regurgitation as quantified by cardiac magnetic resonance. J Am Soc Echocardiogr 2010, 23:880-6.

131. Iriart X, Montaudon M, Lafitte $S$, Chabaneix J, Reant $P$, Balbach $T$, Houle $H$ Laurent F, Thambo JB: Right ventricle three-dimensional echography in corrected tetralogy of fallot: accuracy and variability. Eur J Echocardiogr 2009, 10:784-92

132. Mueller M, Rentzsch $A$, Hoetzer $K$, Raedle-Hurst $T$, Boettler $P$, Stiller $B$, Lemmer J, Sarikouch S, Beerbaum P, Peters B, Vogt M, Vogel M, AbdulKhaliq $\mathrm{H}$ : Assessment of interventricular and right-intraventricular dyssynchrony in patients with surgically repaired tetralogy of Fallot by two-dimensional speckle tracking. Eur J Echocardiogr 2010, 11:786-92.

133. Raman SV, Cook SC, McCarthy B, Ferketich AK: Usefulness of multidetector row computed tomography to quantify right ventricular size and function in adults with either tetralogy of Fallot or transposition of the great arteries. Am J Cardiol 2005, 95:683-6.

134. Norgard G, Rosland GA, Segadal L, Vik-Mo H: Hemodynamic status in repaired tetralogy of Fallot assessed by Doppler echocardiography and cardiac catheterization. Comparisons with healthy subjects and elucidation of factors associated with cardiorespiratory function. Scand J Thorac Cardiovasc Surg 1993, 27:41-8.

135. Wald RM, Lyseggen E, Oechslin EN, Webb GD, Silversides CK: Variability in surgical referral patterns for pulmonary valve replacement in adults with repaired tetralogy of fallot. Congenit Heart Dis 2009, 4:231-8.

136. van der Wall EE, Mulder BJ: Pulmonary valve replacement in patients with tetralogy of Fallot and pulmonary regurgitation: early surgery similar to optimal timing of surgery? Eur Heart J 2005, 26:2614-5.

137. Prakash A, Powell AJ, Geva T: Multimodality noninvasive imaging for assessment of congenital heart disease. Circ Cardiovasc Imaging 2010, 3:112-25.

138. Gottlieb D, Kunal T, Emani S, Aikawa E, Brown DW, Powell AJ, Nedder A, Engelmayr GC, Melero-Martin JM, Sacks MS, Mayer JE Jr: In vivo monitoring of function of autologous engineered pulmonary valve. J Thorac Cardiovasc Surg 2010, 139:723-31.

139. Tang D, Yang C, Geva T, Del Nido PJ: Patient-specific MRI-based 3D FSI RV/LV/patch models for pulmonary valve replacement surgery and patch optimization. J Biomech Eng 2008, 130:041010.

140. Tang D, Yang C, Geva T, del Nido PJ: Image-based patient-specific ventricle models with fluid-structure interaction for cardiac function assessment and surgical design optimization. Progress in Pediatric Cardiology 2010, 30:51-62.

141. Ortega M, Triedman JK, Geva T, Harrild DM: LV dyssynchrony measured by MRI speckle tracking is associated with VT and death in repaired tetralogy of Fallot. Circulation 2009, 120:S575.

142. Bove EL, Kavey RE, Byrum CJ, Sondheimer HM, Blackman MS, Thomas FD: Improved right ventricular function following late pulmonary valve replacement for residual pulmonary insufficiency or stenosis. J Thorac Cardiovasc Surg 1985, 90:50-5.

143. Ilbawi MN, Idriss FS, DeLeon SY, Muster AJ, Berry TE, Paul MH: Long-term results of porcine valve insertion for pulmonary regurgitation following repair of tetralogy of Fallot. Ann Thorac Surg 1986, 41:478-82.

144. Kanter KR, Budde JM, Parks WJ, Tam VK, Sharma S, Williams WH, Fyfe DA: One hundred pulmonary valve replacements in children after relief of right ventricular outflow tract obstruction. Ann Thorac Surg 2002, 73:1801-6, discussion 1806-7.

145. Oosterhof T, Meijboom FJ, Vliegen HW, Hazekamp MG, Zwinderman AH, Bouma BJ, van Dijk AP, Mulder BJ: Long-term follow-up of homograft function after pulmonary valve replacement in patients with tetralogy of Fallot. Eur Heart J 2006, 27:1478-84.
146. Kogon B, Plattner C, Kirshbom P, Kanter K, Leong T, Lyle T, Jennings S, McConnell M, Book W: Risk factors for early pulmonary valve replacement after valve disruption in congenital pulmonary stenosis and tetralogy of Fallot. J Thorac Cardiovasc Surg 2009, 138:103-8.

147. Lindsey CW, Parks WJ, Kogon BE, Sallee D, Mahle WT: Pulmonary valve replacement after tetralogy of Fallot repair in preadolescent patients. Ann Thorac Surg 2010, 89:147-51.

148. van Straten A, Vliegen HW, Lamb HJ, Roes SD, van der Wall EE, Hazekamp MG, de Roos A: Time course of diastolic and systolic function improvement after pulmonary valve replacement in adult patients with tetralogy of Fallot. J Am Coll Cardiol 2005, 46:1559-64.

doi:10.1186/1532-429X-13-9

Cite this article as: Geva: Repaired tetralogy of Fallot: the roles of cardiovascular magnetic resonance in evaluating pathophysiology and for pulmonary valve replacement decision support. Journal of Cardiovascular Magnetic Resonance 2011 13:9.

\section{Submit your next manuscript to BioMed Central and take full advantage of:}

- Convenient online submission

- Thorough peer review

- No space constraints or color figure charges

- Immediate publication on acceptance

- Inclusion in PubMed, CAS, Scopus and Google Scholar

- Research which is freely available for redistribution

Submit your manuscript at www.biomedcentral.com/submit
C) Biomed Central 